\title{
5. PHYSICAL PROPERTIES MODELING AND SEISMIC STRATIGRAPHY AT DEEP SEA DRILLING PROJECT LEG 93 SITES IN THE WESTERN NORTH ATLANTIC ${ }^{1}$
}

\author{
Brian N. M. Biart, Department of Earth Sciences, The Open University, Milton Keynes ${ }^{2}$
}

\begin{abstract}
Physical properties data obtained aboard ship on Leg 93 were used to construct a physical properties stratigraphy in which units were delineated by changes in properties, termed "breaks." Various velocity functions were used to explore the relationship of depth to two-way traveltime. Two methods were used to construct reflection coefficient logs of the reflectivity at unit boundaries: (1) a qualitative assessment of physical property variation and (2) an average impedance computed from corrected velocity and density data. These logs were used to derive synthetic seismograms for correlating recovered core material with the site survey reflection profiles.

The correlations agreed reasonably well with lithological interpretation, but also explained how the closely spaced reflections, particularly from horizons within the lithified sediments (below $800 \mathrm{~m}$ at Site 603 ), interfere to produce the seismic image on the site survey profiles. In particular, at Site 603, Horizon A is due to reflections from the top and bottom of a radiolarian-rich hemipelagic claystone, and Horizon $\beta$ is reversed in polarity as a result of the newly discovered sandy turbidite formation overlying the Blake-Bahama Formation.

The chronostratigraphic significance of Horizon $\mathrm{A}^{\mathrm{c}}$ was investigated at Site 605. Lithological interpretation parallels biostratigraphy, but the physical properties stratigraphy (more closely related to seismic reflections) appears discordant.
\end{abstract}

\section{INTRODUCTION}

A routine objective for shipboard scientists is the correlation of core material with seismic reflection data. These data are in two forms: (1) site survey seismic reflection profiles produced prior to the cruise, and (2) reflection profiles shot with Challenger's own array. The latter are of generally lower quality but are more reliable with respect to positioning of the hole.

From such surveys, the sedimentary column may be divided into seismostratigraphic units defined by prominent reflectors that may also be regionally significant, being traceable for long distances within the basin. Several such reflectors subcrop at Leg 93 sites, and all but the deepest Jurassic(?) horizons were penetrated at Site 603 . Sites 604 and 605 on the New Jersey Transect recovered material down to below Horizon A*.

The aim of this paper is the lithological interpretation of these regionally significant reflectors and the intervening minor events. These reflectors are produced by contrasts in the acoustic impedance of the sedimentary strata. Such contrasts and their corresponding reflections may bear a one-to-one correlation, but the relationship need not be so simple. Individual reflectors may be produced by a number of closely spaced contrasts or by a gradient of impedance caused by a transition in the physical properties. The effect of attenuation on seismic reflectivity was not investigated on Leg 93.

Sedimentary logging of the recovered core material permits construction of a lithostratigraphy. Individual units, although not necessarily homogeneous, may be considered to have a distinct character when compared

\footnotetext{
${ }^{1}$ van Hinte, J. E., Wise, S. W., Jr., et al., Init. Repts. DSDP, 93: Washington (U.S. Govt, Printing Office).

2 Present address: Exploration Consultants Ltd., Highlands Farm, Greys Road, Henleyon-Thames, Oxon RG9 4PS United Kingdom.
}

to adjacent units. Thus, it is not unreasonable to expect impedance contrasts to exist at unit boundaries, and, consequently, for lithologic units to be correlated with seismostratigraphic units (i.e., for reflectors to be correlated with lithologic unit boundaries). In practice, this assumption is sufficient to establish at least an initial interpretation. If the contrasts are very marked and the sediments are acoustically quiet between them, correlation is straightforward. It becomes more difficult as the contrasts decrease in amplitude and the background noise of intraunit reflectors increases: then, accurately matching the boundary with a particular black (or white) line on the reflection profile becomes nontrivial. The problem is divisible into two components: (1) establishing an accurate velocity function, and (2) calculating reflectivities for recognized boundaries. The latter gives the amplitude of reflections, and the former permits accurate positioning of the reflections with respect to the timesection being interpreted. Both these problems can be resolved by constructing a synthetic seismogram derived from measurements of the in situ physical properties. The modeling scheme, which assumes horizontal layering of all surfaces, will be described for Site 603 and then applied to sites on the New Jersey Transect. Figure 1 shows the site survey profile for Site 603, Conrad line 2101-77, with the regional reflectors labeled (see site chapter, this volume, for a detailed description of the seismic correlation).

\section{PHYSICAL PROPERTIES MODELING, SITE 603}

The 24-fold multichannel site survey profile was processed at Lamont-Doherty Geological Observatory with Berg-type deconvolution (maximum entropy) and a bandpass filter between $12-40 \mathrm{~Hz}$.

The simplest means of correlation is to measure the in situ physical properties by means of standard petrophysical techniques-wireline logs, which can then be 


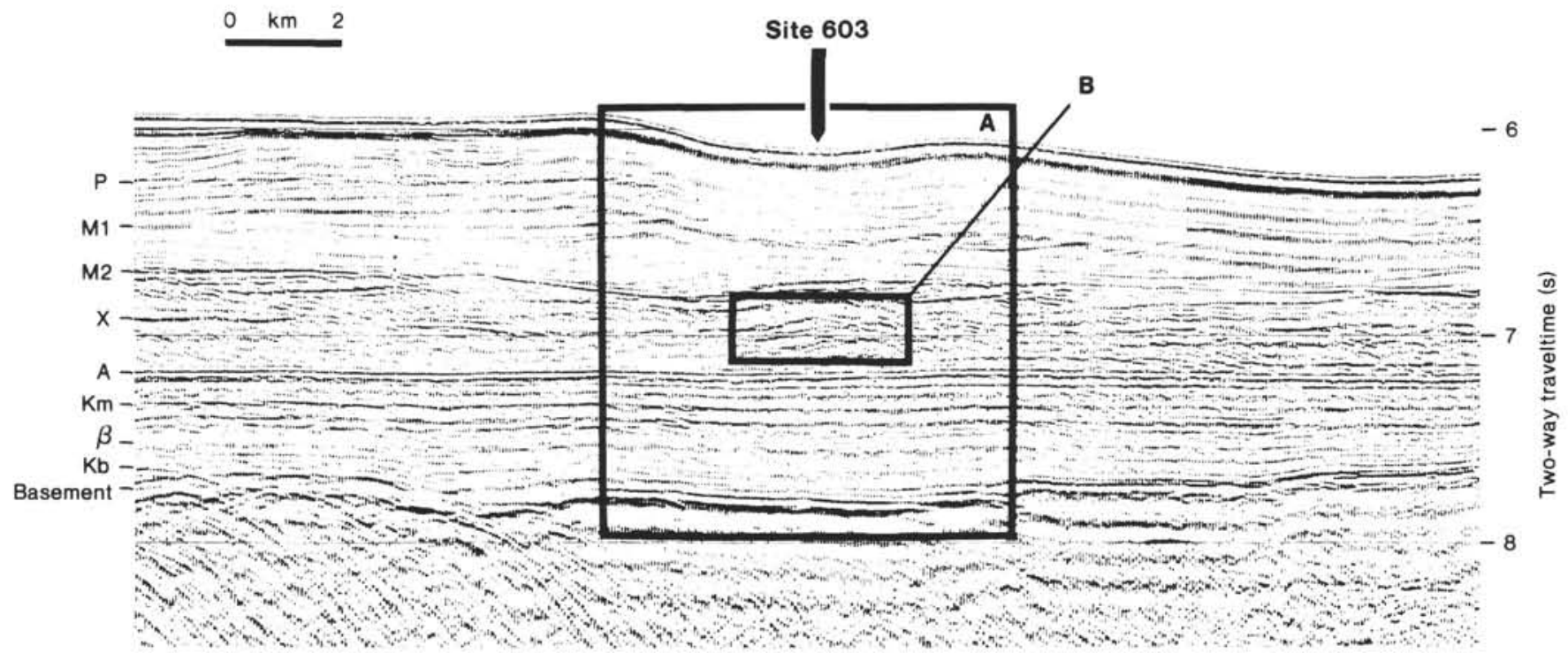

Figure 1. Site survey profile (Conrad line 2101-77) across Site 603, showing regional seismic horizons. Boxes A and B refer to Figures 4 and 5 , respectively.

used for synthetic modeling of the seismic reflections. Downhole logging was not possible at any Leg 93 sites, so the physical property measurements made aboard ship, which constitute an alternative data set, must be used alone. Owing to pressure and temperature changes and disturbance by drilling, properties measured at the surface cannot be used directly to describe the in situ properties. Further, the measurements are all made at discrete points, in contrast to the more continuous data obtained by wireline techniques. For these reasons, modeling using physical properties data is less precise; the velocity and density measurements can be used to produce an impedance log directly, with breaks assigned to points between samples, but this log contains too much noise to permit modeling.

High-frequency random noise caused by the poor quality of the data degrades the final model but can be reduced by filtering. More important, with respect to frequency, is noise that is spatially biased as a result of systematic sampling. Samples are taken once per section, between 50 and $90 \mathrm{~cm}$, where possible (there are seven sections in a fully recovered core). Minor lithologies are measured once per core, even though they constitute less than $14 \%(1 / 7)$ of a core. This tends to favor minor lithologies, while inadequately accounting for those lithologies which are not recovered. Further, the unrecovered material is likely to differ markedly from the recovered section in competence and velocity. The averaged physical properties will thus err systematically, causing velocity to be overestimated and compressing the time scale for further modeling.

\section{Units at Site 603}

"Breaks" in the physical properties were picked from the graphs of each parameter measured. At Site 603, the polarity of each break was recorded against depth and assigned a qualitative weighting factor between 1 and 4 , depending on the number of parameters in which the break appeared and their apparent magnitude. Nine major and 37 minor breaks can be identified, constituting a physical properties stratigraphy of 10 units and a total of 44 subunits (Fig. 2).

Unit 1 extends from the seafloor to $110 \mathrm{~m}$ and represents an interval of unconsolidated sediment with low shear strength. It has one subdivision, drawn where shear strength levels off following initial water loss. Unit 2 has high shear strength and exhibits even trends in all properties. Carbonate content is very variable. It has seven subunits, defined by minor changes in velocity and bulk gravimetric properties. Unit 3 is poorly sampled; all its measurements were made on core recovered from Hole 603 , and it may be somewhat artificial. Porosity and water content falter in their steep downward trend, in part reflecting the difference between material recovered by hydraulic piston coring and that by rotary coring. Two subdivisions are drawn at minor changes in gravimetric measurements. Unit 4 is sampled at frequent intervals, showing that the sediments have undergone sufficient diagenesis to withstand rotary coring. Four subdivisions are defined, one by a slight elevation of carbonate content. Unit 5 is distinguished by lower densities and increased porosity. Four minor divisions are drawn. Unit 6 , which coincides with the beginning of data from Hole $603 \mathrm{~B}$, is drawn at a rise in velocity and carbonate content. Only one subdivision is seen-the bottom $\sim 17 \mathrm{~m}$ appear as transitional to the succeeding unit (Unit 7). Unit 7 has anomalously high velocities and low densities. Porosity and water content are not particularly affected, whereas carbonate content is much reduced. There are no subdivisions. Unit 8 is marked by a return to the otherwise uniform trend of Units 1 through 6. Generally, it displays more variability, making the definition 
PHYSICAL PROPERTIES MODELING, LEG 93

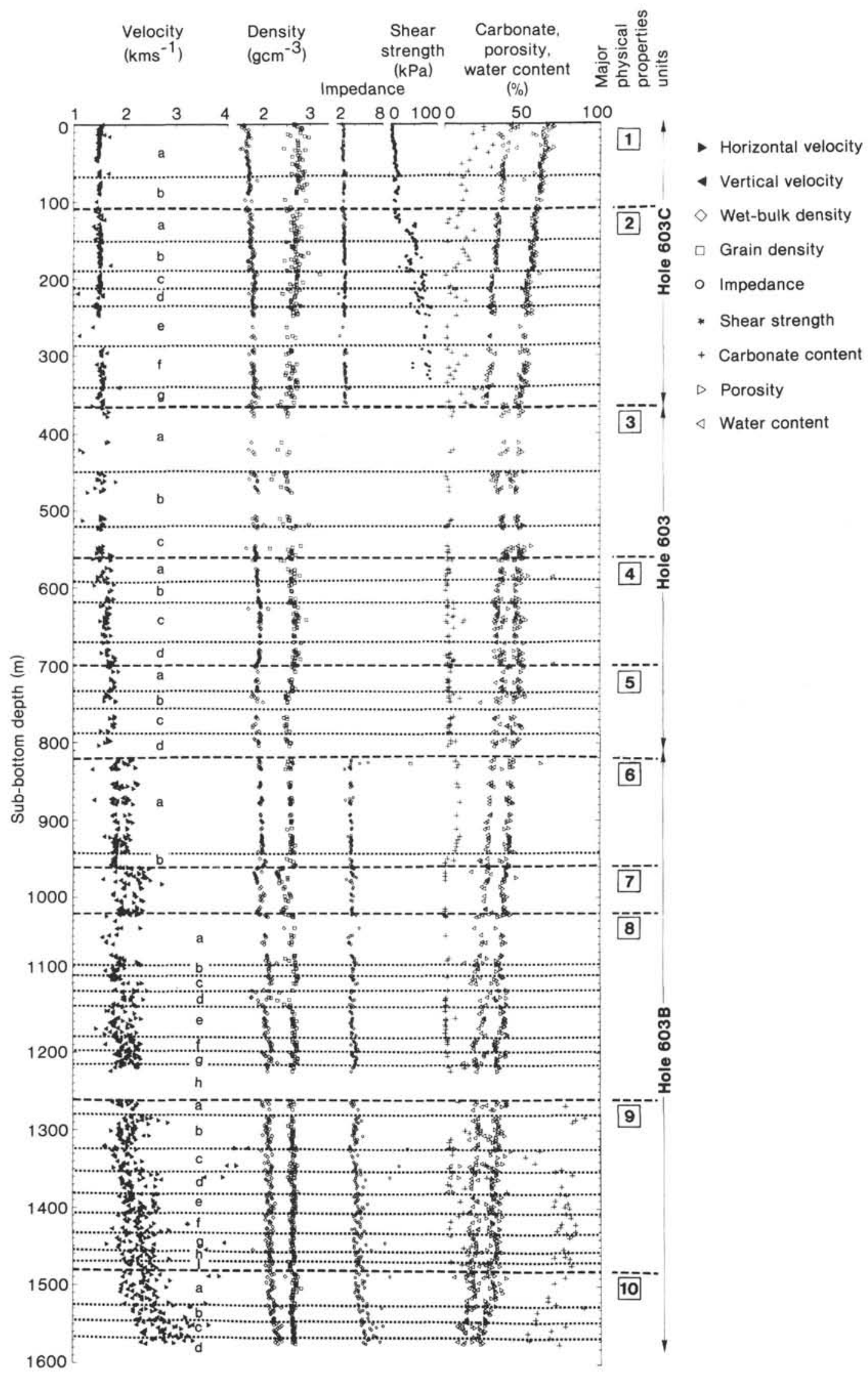

Figure 2. Summary of physical properties for Site 603 , including the physical properties stratigraphy. Sub-bottom depths are uncorrected for vertical deviation of the drill hole. 
of subunit boundaries, in particular Subunit 8d, much more definite. Unit 9 is defined by a substantial increase in the carbonate content measured from some samples. The overall carbonate content for this unit is strongly bimodal. Nine subdivisions are recognized from minor changes of velocity and gravimetric measurements. Low recovery from Subunit $8 \mathrm{~h}$ means that the Unit $8 / 9$ boundary is open to question; Unit 9 may include Subunit $8 \mathrm{~h}$. Unit 10 shows steepened trends in velocity and wet-bulk density. Carbonate content is reduced and is no longer bimodal. Four subunits are drawn.

\section{Modeling Techniques}

A reflection-coefficient time series was constructed using the two-way traveltime to these depths, calculated by the schemes described below. Modeling was performed in the time domain by convolution of this series with a source waveform to give a synthetic seismogram for the hole. In order accurately to model the interference of reflections from adjacent horizons, this waveform is constructed so that its amplitude and phase spectra match those of the filters used in processing the profile with which the model is to be compared. The important characteristics are the band-width (between high- and lowcut frequencies) and the gradients of rolloff beyond these limits.

This method assumes that the material recovered from the hole is a fair representation of the much larger body of sediment sampled by seismic imaging (Fig. 3). This area is reduced by the statistical methods employed in processing multichannel profiling systems, but remains several orders of magnitude greater than the cross-sectional area of recovered core, $137 \mathrm{~cm}^{2}$. However, the biggest hindrance to accurate modeling results from the great disparity between the shipboard conditions under which

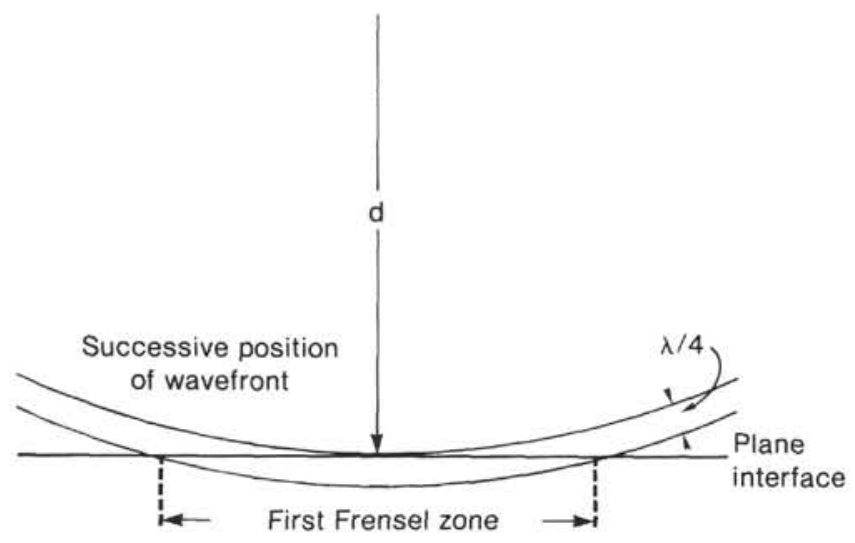

For spherical waves, area $=\left[(d+\lambda / 4)^{2}-d^{2}\right] \pi$.

If $\lambda / 4=12 \mathrm{~m}$ and $\mathrm{d}=3 \mathrm{~km}$ : area $=227,000 \mathrm{~m}^{2}$.

Cross-sectional area of core $=0.0137 \mathrm{~m}^{2}$

Figure 3. Comparison of the areas sampled by core recovery and seismic survey. I have assumed a spherical wave in calculating the area that produces constructively interfering reflected waves which control the resolution. This area is reduced by the statistical methods employed in processing multichannel data, but remains several orders of magnitude above the area of recovered core. $d=$ depth. the measurements are made and conditions downhole which are to be modeled. This means that the velocity data cannot be used directly to produce an integrated transit time to each depth. Even if the physical property logs exhibit prominent breaks, these cannot be accurately positioned on the time-section and so cannot be reliably tied to the reflectors. Thus the development of a velocity function is crucial to the accuracy of the final correlation.

In order to solve this problem, a number of empirical velocity functions were compared. The most primitive of these assumes that velocity is some simple function of depth. Houtz (1973) investigated fitting higher-order polynomials to sonobuoy data, but concluded that the improvement was negligible, considering the accuracy of the data upon which it was based. Even though velocity inversions cannot be incorporated, the accuracy of reflector depths calculated from arrival times was only slightly below the resolution of seismic imaging (about $15 \mathrm{~m})$. Houtz (1973) gives several velocity functions for various parts of the world's oceans. His function, based on 87 measurements from the Hatteras Abyssal Plain, was used to construct model 1 : Velocity $(\mathrm{km} / \mathrm{s})$,

$$
V=0.58+1.24 t,
$$

where $t=$ one-way reflection time (s) (Tucholke et al., 1982 , give $V=1.68+1.16 t$ ).

Model 2 is based on the results of nearby drilling. Benson, Sheridan et al. (1978) calculated sediment velocity at Sites 388 and 391 after correlating cores with the site survey profiles. (These data were used to predict the depth at which reflectors would be encountered on Leg 93.) No correlation can be made between the upper part of the sections at Sites 388 and 603, where Model 2 severely overestimates velocity. This is to be expected, considering the variation in lithology between the two sites: Site 388 has $50-150 \mathrm{~m}$ of calcareous silty clay overlying dark green clay. The silty clay has a higher sonic velocity $(1.60 \mathrm{~km} / \mathrm{s})$ than the hemipelagic clay of Site $603(1.50$ $1.55 \mathrm{~km} / \mathrm{s}$ ). Preliminary correlation on Leg 93 of lithology with reflectors gives a third velocity function, which involves a number of velocity inversions (see Site 603 site chapter, this volume), but implies we know the answer in advance of modeling.

A fourth velocity function has been used to construct a synthetic seismogram, with an improved fit to the profile (Model 3). It is simple, in that it does not include any velocity inversions, and differs from other models in the slower velocity used to model the upper sediments. Model 1 serves as a first approximation: the Horizon A complex and Horizon $\mathrm{K}_{\mathrm{b}}$ give reasonable fits, but all velocities above are overestimated (Fig. 4). Model 2 gives a much closer match: the Horizon A complex gives a good fit, as do Horizons X and M2. Horizons $\mathrm{M} 1$ and $\mathrm{P}$ are not so close, but are recognizable despite their offset (Fig. 4). With Model 3, a static correction to Model 2 to correctly align Horizon A, Horizons X, M2, $\mathrm{M} 1$, and $\mathrm{P}$ give good ties, but there is still a large discrepancy in the upper part of the section. (It is not known why this correction is necessary; possibly the seabed has been located at a different peak.) 


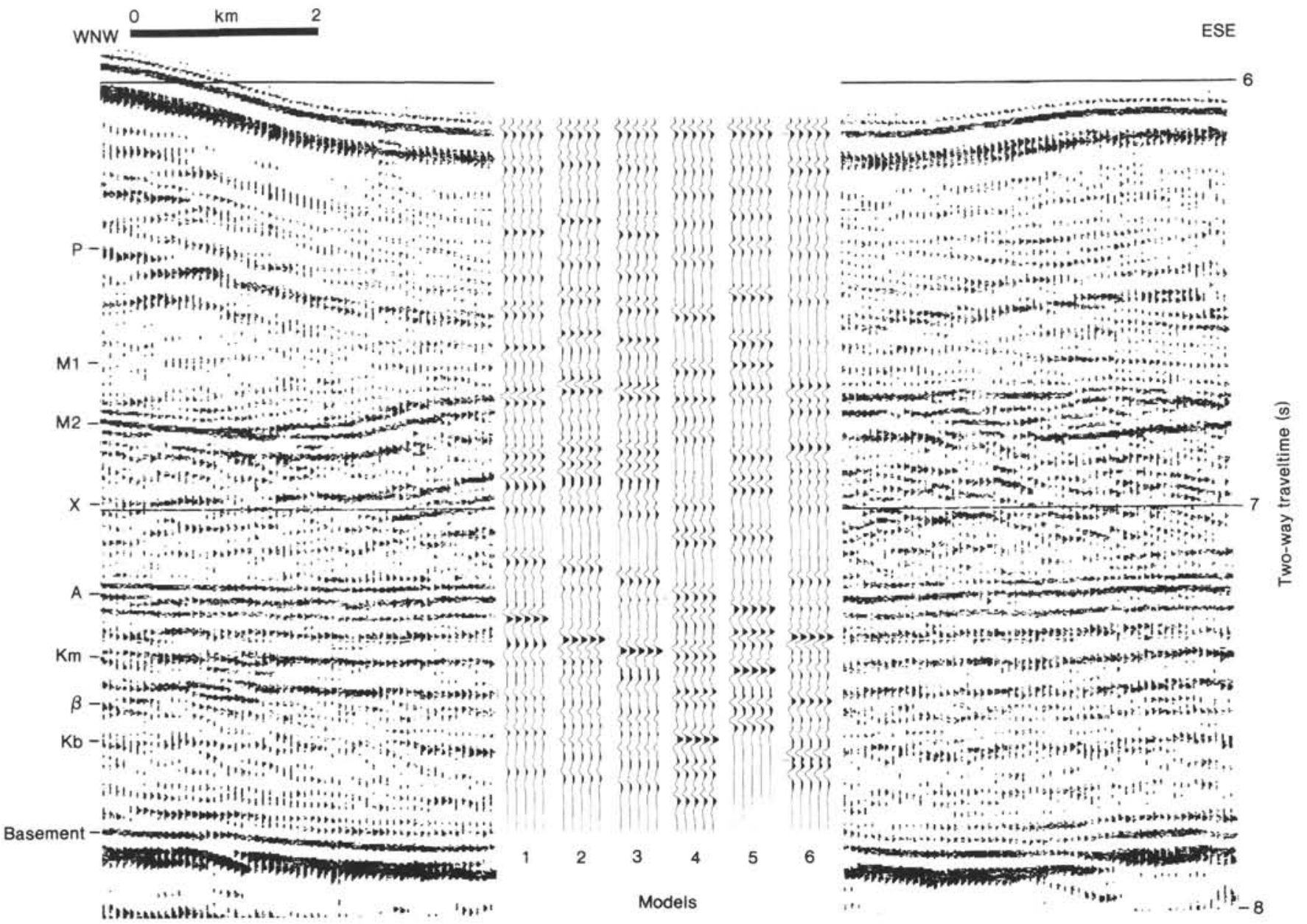

Figure 4. Comparison of models for Site 603. The models have been inserted at the site location, and differ primarily in the velocity function used in their construction. 1. Sonobuoy data (Houtz, 1973). 2. Drilling data from Site 391 (Benson, Sheridan, et al., 1978). 3. Drilling data from Site 603 (site chapter, this volume). 4. Simplified velocity function (this chapter). 5. Physical properties model. 6. Model 5 including correction for low recovery.

Model 4 gives reasonable ties for Horizon $\mathrm{Kb}$ and and Horizon $\beta$. Horizon $\mathrm{Km}$ is accurate in depth, but reversed in polarity. The Horizon A complex gives a good match. Poor recovery for the interval above Horizon A prevents modeling over this interval (Cores 603B-5 through 603B-11M, $820 \mathrm{~m}-900 \mathrm{~m}$ ). Hence, there is no "trailing" reflection that would otherwise interfere with the onset of the Horizon A complex. The tie at Horizon X is not so close, but it is clear that a number of strong reflectors are interfering. Horizon X swells at Site 603 and bifurcates, making accurate interpretation difficult (Fig. 5). Van Hinte (personal communication, 1984) picks the black loop at $6.96 \mathrm{~s}$ (two-way traveltime, TWT), whereas I prefer the black loop at $6.91 \mathrm{~s}$ (TWT). It is debatable whether a better "reflector" might not be the preceding white loop at $6.88 \mathrm{~s}$ (TWT). Horizon M2 correlates well; a double peak may be explained as interference with one of the onlapping "contourite" clinoforms. Horizons M1 and $\mathrm{P}$ show reasonable fits, as do some of the higher clinoforms.

The development of these models demonstrates that synthetic seismograms can be generated using the physical property stratigraphy. The presumption that we know
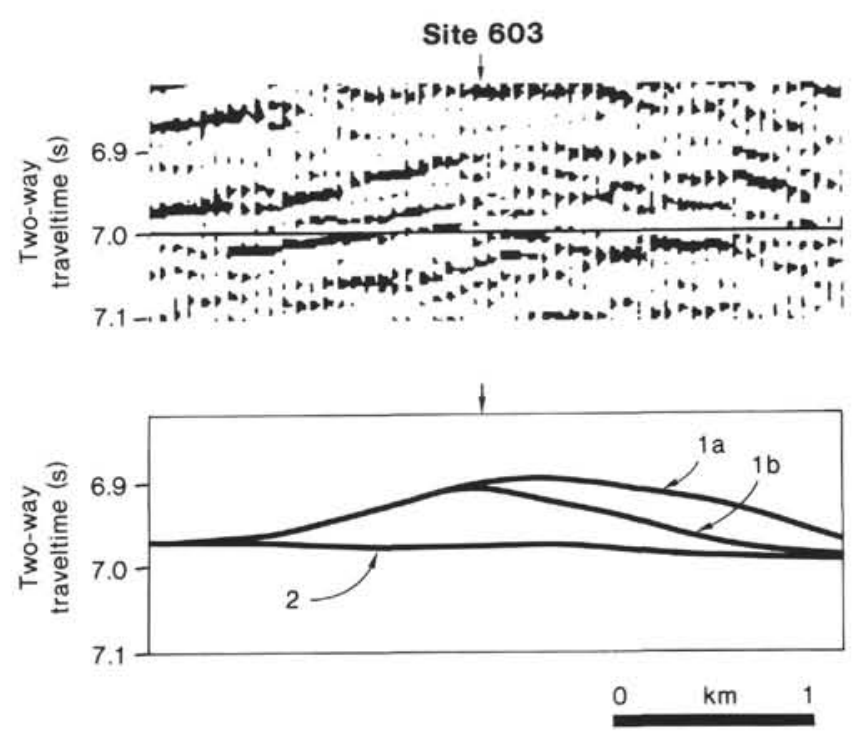

Figure 5. Detail of site survey profile for Site 603, showing ambiguous interpretation of Horizon X near the site. (1a) J. E. van Hinte (personal communication); (1b) this paper; (2) alternative interpretation. 
where to tie Horizon A is an unfortunate necessity caused by the difficulty of accurately modeling the velocity function of the upper sediments. Had basement been reached, there would have been definite ties at each end of the model constraining the number of possible solutions. Our confidence in the models is reduced by the need to have an accurate correlation in order to construct them.

For this reason, two more models have been constructed, based on the method of Shipley (1983) in order to achieve a more accurate estimate of both the velocity function and the reflection coefficient at each break. Cross-plots of porosity versus vertical velocity and density versus vertical velocity are used to establish empirical functions relating these parameters at a particular site (Fig. 6). Porosity is then corrected for rebound, using the curve of Hamilton (1976) extrapolated in the manner of Shipley (1983) (Fig. 7). The point of zero porosity rebound, corresponding to fully lithified sediment, is lower at Site 603 (than at Site 534, where Shipley developed his method, but still equates with the top of Horizon $\beta$. Velocity is calculated from corrected porosity and then this derived velocity is used to calculate a value for in situ density. The values of velocity and density are then averaged for each unit. A reflection coefficient for each boundary and two-way traveltime are cal-

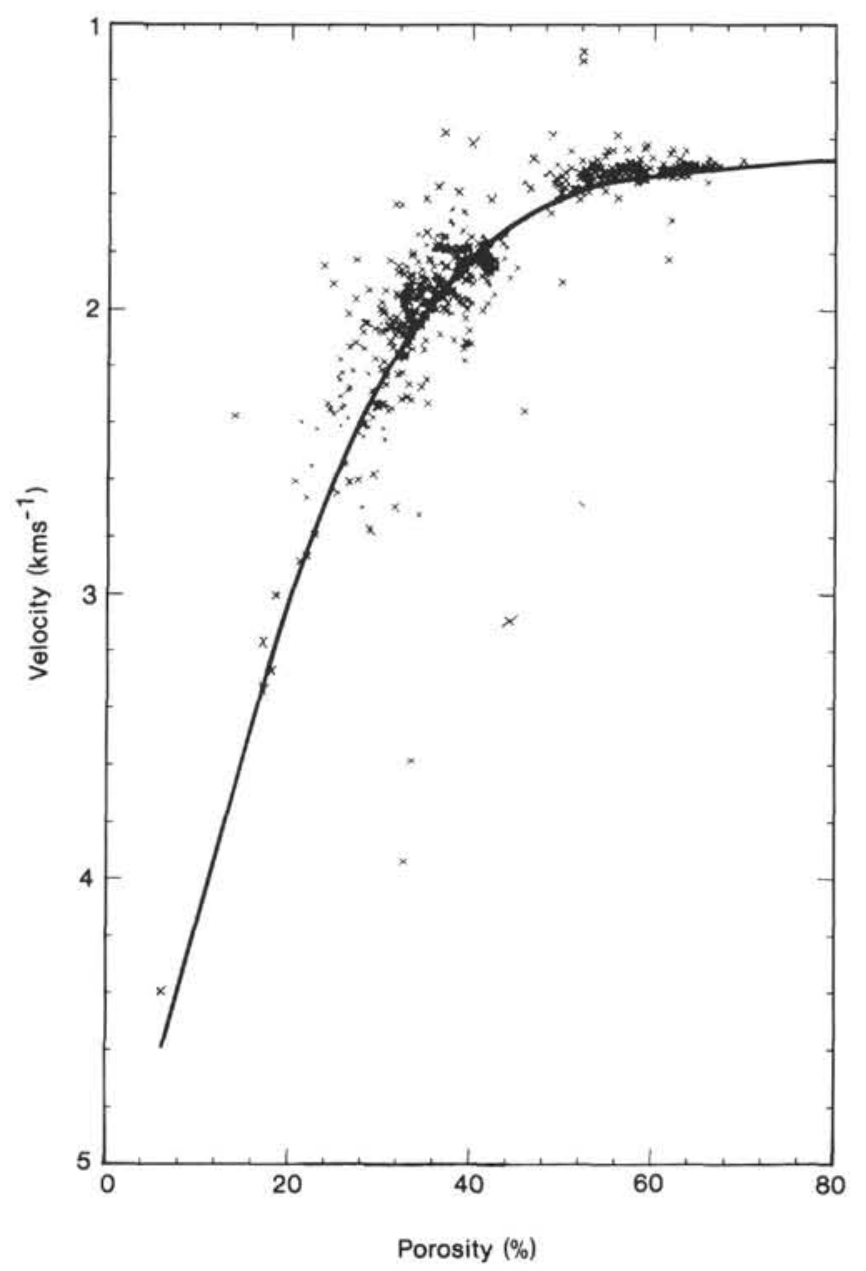

culated from these averaged values. Shipley (1983) used stratigraphy from the lithostratigraphy report: at Site 603 the number of layers produced in this way is insufficient for modeling. All lithostratigraphic boundaries coincide with a physical property break, but there are many more breaks. Therefore, the physical property stratigraphy has been used, Model 5 (Fig. 4).

This approach assumes that the recovered section is an unbiased sample of the whole column, but it is quite possible that the unrecovered portion was lost just because it was different. Shipley (1983) suggests that all unrecovered material may be assumed to have been argillaceous and to have been lost by washing. This assumption is obviously an "end-member" in the set of possible lithological columns, but as such it gives an estimate of the maximum error in the method. Model 6 (Fig. 4) has been calculated by assuming that the unrecovered material is mud or mudstone. The unrecovered part of each interval is assigned the velocity and density of argillaceous material. These values are calculated by cross-plotting velocity and density versus porosity with regard to lithology and a relative value is calculated for the "argillaceous" portion. The properties are than averaged over the whole interval and multiplied to give a mud-corrected acoustic impedance. In general, both the

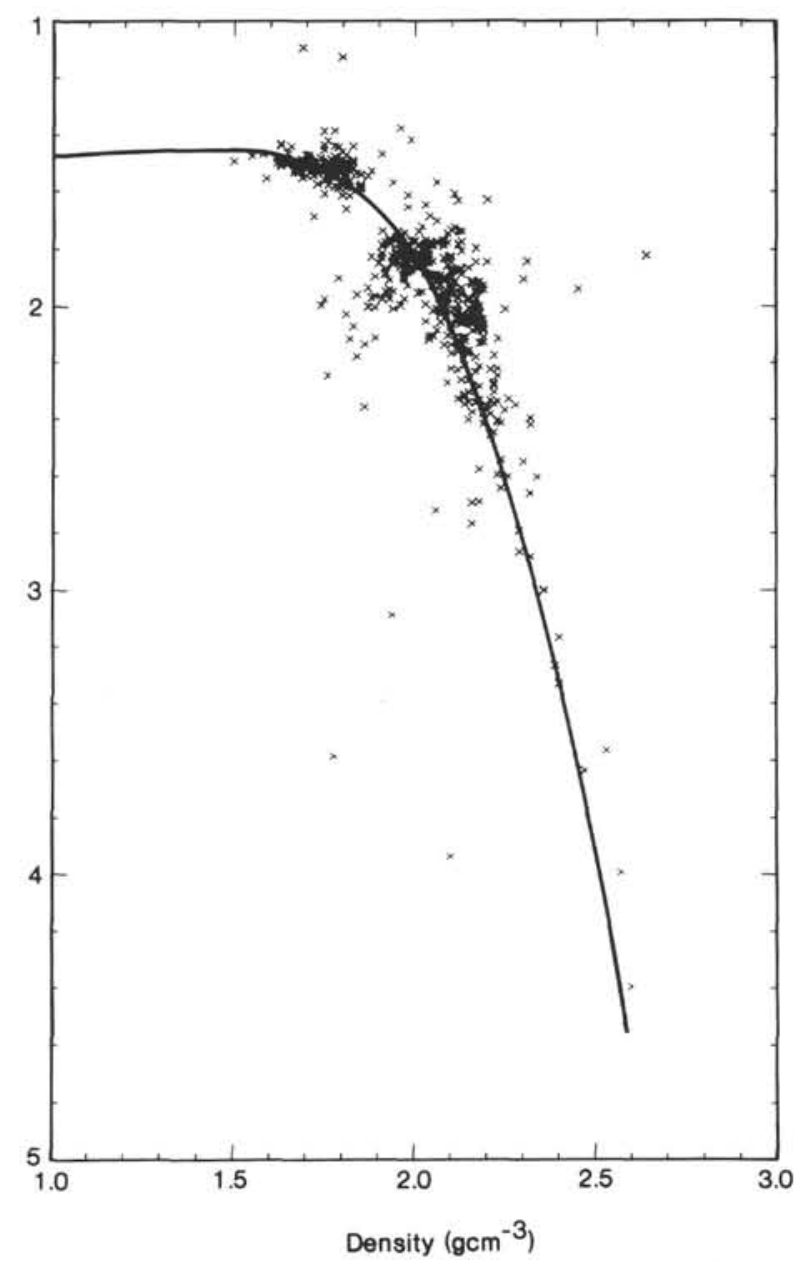

Figure 6. Cross-plots, Site 603. 


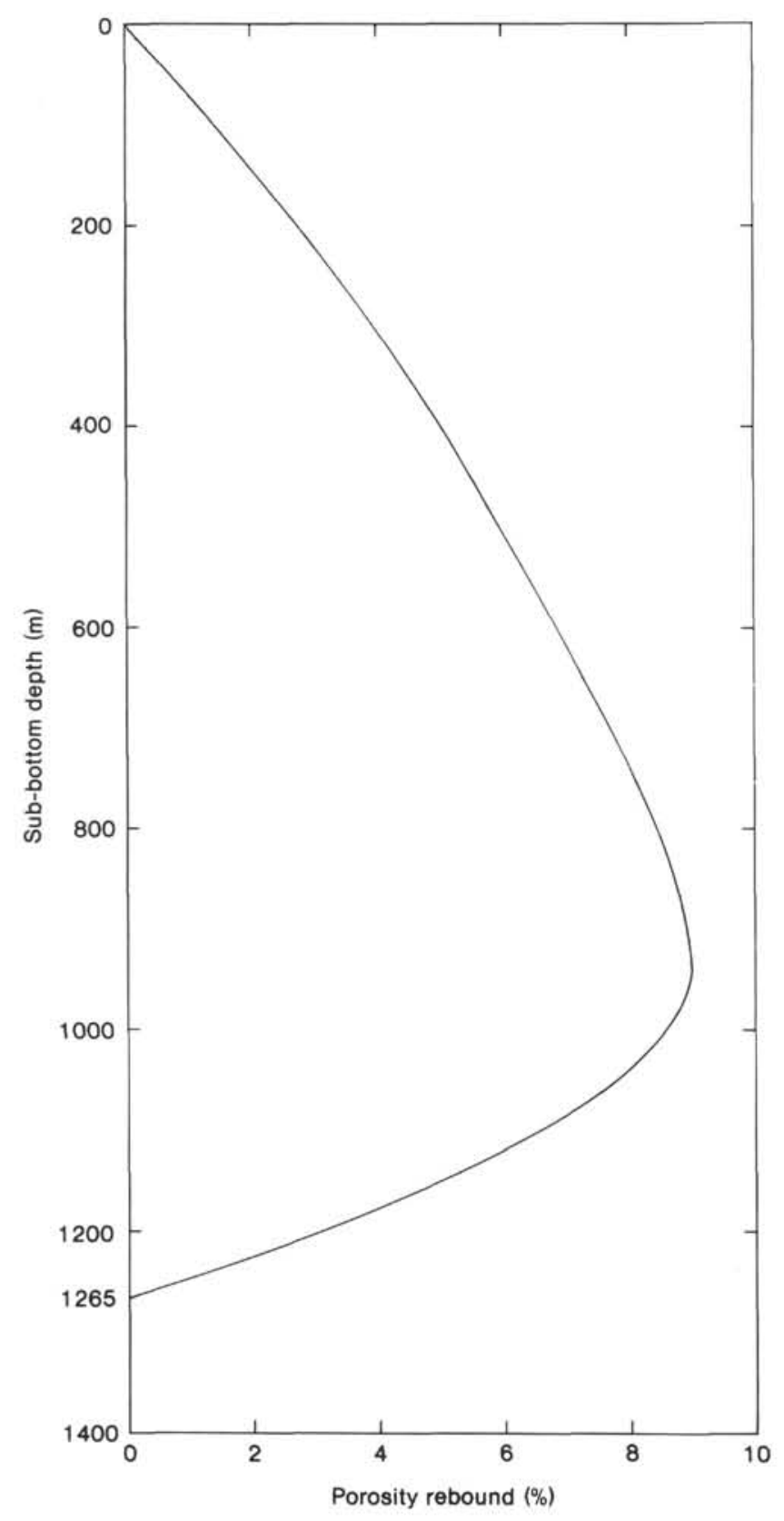

Figure 7. Porosity rebound for Site 603. After Hamilton (1976) and Shipley (1983).

transit time for a given layer and the reflection coefficients between layers are increased by this correction, poorly recovered sections being more affected. This model gives a very reasonable fit at all horizons (Fig. 4) and will be used for subsequent correlation of lithology with the seismic profile.

\section{Lithological Interpretation of Reflectors, Site 603}

It should be stressed that these models are based on the physical properties stratigraphy and not on any chrono- or lithostratigraphy. Poor recovery may mean that significant boundaries have been missed because no measurements of the properties were possible; in such cases, the model has been left blank and constant veloc- ity has been assumed (e.g., Cores 603B-45 through -49). Also, the model assumes that all boundaries are shown by porosity breaks. With increased lithification this is not so apparent. Thus the velocity log has been used to correct amplitude, although the velocity function remains dependent on the porosity derivation.

Based on this modeling, the correlations in Table 1 were made. The depths used in Table 1 are drill string depths, corrected to true vertical depths before modeling because the drill string deviated considerably from vertical.

\section{Horizon Kb}

Horizon $\mathrm{Kb}$ is drawn at $7.6 \mathrm{~s}$ (TWT) and correlates with $1440 \mathrm{~m}$ sub-bottom. This is the top of physical properties Subunit $9 \mathrm{~h}$, which is characterized by variable lithology. In particular, sedimentation starts to include turbidites, which increase in important upward. Horizon $\mathrm{Kb}$ is a discontinuous reflector at Site 603 and is not accurately modeled. The minor unit ( $9 \mathrm{~h})$ shows a change of porosity from relatively high (physical properties Subunit $9 \mathrm{~g}$ ) to low (physical properties Subunit 9i) and contains the deepest occurrence of low-carbonate formations deposited below the calcite compensation depth, CCD. (The physical properties of lithologic Unit V, $1215 \mathrm{~m}$ to the total depth of $1585.2 \mathrm{~m}$, are much more variable than in units above. This renders the assumption that the reflectivity can be accurately modeled by taking samples at $1.5 \mathrm{~m}$ or even further apart less valid.) Horizon $\mathrm{Kb}$ marks the approximate boundary between Barremian and Hauterivian sediments. Note that the name "Horizon $\mathrm{Kb}$ " is inappropriate if the horizon is meant to be correlated with the basal Cretaceous; a better label might be "K1," signifying a horizon within the Lower Cretaceous.

\section{Horizon $\beta$}

Horizon $\beta$ is a very widespread reflector over much of the North American Basin. It marks the change from carbonate- to noncarbonate-dominated sedimentation caused by a shallowing of the CCD in mid Early Cretaceous times (Tucholke, 1981). Horizon $\beta$ is normally a strongly positive event produced by the impedance contrast between the two lithologies. At Site 603, it is drawn at $7.42 \mathrm{~s}$ (TWT) which corresponds to the interference product of reflections from physical property breaks at $1216 \mathrm{~m}$ and $1264 \mathrm{~m}$. The black loop at $7.42 \mathrm{~s}$ TWT in Figure 4 actually is correlated with approximately $1240 \mathrm{~m}$ within the poorly recovered unit. These depths set bounds to physical properties Subunit $8 \mathrm{~h}$, which comprises unlithified turbidites for which no measurements could be made (Section 603B-45-2 through Core 603B-48). The reflector picked is laterally continuous, although it does develop a double-peaked character $3 \mathrm{~km}$ along the section to the southeast, which, it may be argued, supports the interference origin. Correlations of Horizon $\beta$ at other sites in the North American Basin give a variety of ages (see Table 2), thought to result from a depth change in the carbonate compensation depth. In consequence, the reflector is diachronous (Tucholke, 1981). 
Table 1. Correlation of seismic reflectors, Site 603.

\begin{tabular}{|c|c|c|c|c|c|c|}
\hline \multirow[b]{2}{*}{ Horizon } & \multicolumn{3}{|c|}{ Depth } & \multirow[b]{2}{*}{ Age } & \multirow{2}{*}{$\begin{array}{l}\text { Phys. prop. } \\
\text { unit (top) }\end{array}$} & \multirow[b]{2}{*}{ Core-Section } \\
\hline & TWT & True & Well & & & \\
\hline $\mathrm{P}$ & 6.35 & 190 & 190 & Pliocene & $2 c-d$ & $603 \mathrm{C}-22-4$ \\
\hline M1 & 6.6 & 366 & 366 & u. Miocene-Pliocene & $2 \mathrm{~h}$ & $603-16-3$ \\
\hline M2 & 6.75 & 563 & 563 & u. Miocene & $3 \mathrm{c}$ & $603-27-1$ \\
\hline $\mathrm{x}$ & 6.9 & 700 & 700 & $\begin{array}{l}\text { m. Miocene-1, u. } \\
\text { Miocene }\end{array}$ & $5 \mathrm{a}$ & $603-42-2$ \\
\hline A complex & $7.15-7.22$ & 953-1011 & $960-1020$ & m. Miocene & $7-8 a$ & $\begin{array}{l}\text { 603B-15-4- } \\
603 \mathrm{~B}-22-1\end{array}$ \\
\hline $\mathrm{Km}$ & 7.3 & 1162 & 1179 & top Aptian-Albian & $8 \mathrm{f}$ & 603B-39-5 \\
\hline$\beta$ & 7.42 & 1240 & 1221 & Barremian & $8 \mathrm{~h}$ & $603 B-47-3$ \\
\hline $\mathrm{Kb}$ & 7.6 & 1440 & 1470 & Barremian-Hauterivian & $9 \mathrm{~h}$ & $603 \mathrm{~B}-71-2$ \\
\hline
\end{tabular}

Note: TWT $=$ two-way traveltime.

Table 2 . The age of Horizon $\beta$.

\begin{tabular}{lll}
\hline \multicolumn{1}{c}{ Black clays } & Limestones & \multicolumn{1}{c}{ Reference } \\
\hline $\begin{array}{l}\text { Barremian } \\
\text { Aptian }\end{array}$ & $\begin{array}{l}\text { Hauterivian } \\
\text { Neocomian }\end{array}$ & $\begin{array}{l}\text { Mountain, 1977 } \\
\text { Benson et al., 1978; Bryan } \\
\text { et al., 1980 }\end{array}$ \\
$\begin{array}{l}\text { mid-Cretaceous } \\
\text { lower Albian- } \\
\text { upper Aptian }\end{array}$ & $\begin{array}{l}\text { Neocomian } \\
\text { Barremian }\end{array}$ & $\begin{array}{l}\text { Tucholke, 1981 } \\
\text { Sheridan, Gradstein, et al., } \\
1983\end{array}$ \\
$\begin{array}{ll}{ }^{\text {a }} \text { Horizon identified as } \beta^{\prime} . & \end{array}$
\end{tabular}

Lithologically, Horizon $\beta$ is usually considered to be due to the impedance contrast between upper Lower Cretaceous black clays and lower Lower Cretaceous carbonates, that is, it is placed at the boundary between the Hatteras and Blake-Bahama formations. At Site 603 this boundary is confused by the deposition of sandy turbidites, which become more important throughout the Hauterivian and constitute over half of Barremian sediments. Thus, the juxtaposition of Aptian/Albian black carbonaceous claystone (lithologic Unit IV) with Neocomian carbonates is fouled by these clastics. It is possible to argue that Horizon $\beta$ should be drawn at $1264 \mathrm{~m}$ and tied to the white loop that corresponds to the top of sediments with high carbonate contents. The negative polarity will then be produced by the boundary of the carbonates with the higher-impedance sands above. Such a conclusion explains the character of Horizon $\beta$ at Site 603 and the difficulty in tracing the reflector from other profiles. In one sense then, as a result of the extra formation, it is fair to say that this is not the classical Horizon $\beta$.

\section{Horizon Km}

Horizon $\mathrm{Km}$ is produced by the interference of three closely spaced impedance contrasts: a positive contrast at $1100 \mathrm{~m}$ and two of reversed polarity at $1085 \mathrm{~m}$ and $1120 \mathrm{~m}$. They correspond to sections 603B-29-4, 603B-31-1 and $603 \mathrm{~B}-32-2$ and to the tops of physical properties Subunits $8 \mathrm{~b}, \mathrm{c}$, and $\mathrm{d}$. Of these, the first two, which bound physical property Unit $8 \mathrm{~b}$, are the more obtrusive on the velocity logs (particularly horizontal velocity), whereas the bulk gravimetric properties show a more marked break at the third depth (Fig. 8). Lithologically, physical properties Subunits $8 \mathrm{~b}$ and $8 \mathrm{c}$ are variegated claystone with a variable amount of coarser terrigenous input. Their red

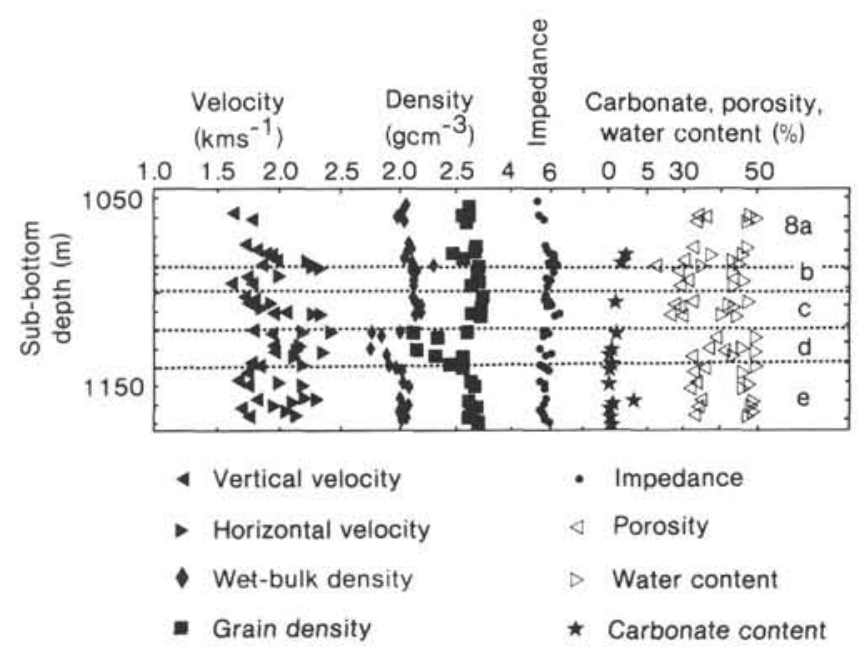

Figure 8 . Physical properties between $1050 \mathrm{~m}$ and $1150 \mathrm{~m}$ sub-bottom, Site 603 .

brown coloration indicates deposition in an oxidizing environment. The carbonate content is variable, but slightly higher than the units above. This is surprising, as a high carbonate content is usually associated with high velocity, and casts some doubt on the validity of the first two breaks. The last break is validated by a change in lithology: deposited in reducing conditions (grey color), physical properties Subunit $8 \mathrm{~d}$ contains negligible carbonate, whereas black claystone is more common. Stratigraphically, this break $(1120 \mathrm{~m})$ equates with the top Aptian. Seen in this light, horizon $\mathrm{Km}$ is either less important than the white loop that immediately succeeds it or, alternatively, horizon $\mathrm{Km}$ should be drawn at the white loop. It is usually drawn between the Plantagenet and Hatteras formations $(1120 \mathrm{~m})$.

\section{Horizon A Complex}

The Horizon A complex is produced by the interference of reflections from the top and bottom of physical properties Unit 7. This corresponds closely with lithologic Unit II: a middle Eocene radiolarian claystone. The upper horizon correlates with a physical properties break at $953 \mathrm{~m}$ (603B-15-4). The study of physical properties over this interval is complicated by variable recovery. The interval above shows little variation and in consequence contributes little to the reflected signal. The double peak 
is explicable in terms of the source wavelet, which has two black loops and one white (cf. the seabed reflection). The very strong lateral persistence of these reflections indicates strong lateral homogeneity. The physical properties of samples that were measured show no sign of more than one break, which is also consistent with the lateral persistence.

The upper horizon is characterized by a marked increase in both horizontal and vertical velocity, and a decrease in density, because of a higher proportion of biogenic silica. Together, these factors suggest that the sedimentary framework is increasingly important to the transmission of sound. Lithologically, this break correlates with the boundary between lithologic Subunit ID and lithologic Unit II (silt-rich claystones above radiolarian claystone). The difference between these two lithologic units is quite marked (Plate 1). Lithologic Subunit ID is a monotonous claystone with silt-sized clasts such as feldspars, some of which show authigenic weathering. Lithologic Unit II is similar, but additionally exhibits abundant veins and cavities, possibly produced by dissolution of calcareous fossil debris. Each vug is packed with lepispheres of opal-CT (Weaver and Wise, 1974; Oehler, 1975) approximately $4 \mu \mathrm{m}$ in diameter. Those lepispheres which seeded adjacent to the vug walls coalesce to form a continuous radiaxial coating. The higher percentage of silica explains the reduced density, and early formation of a strong cement may have helped to preserve a greater proportion of the initial porosity and so explain the higher porosity. Opal-CT is intermediate in the diagenesis of biogenic silica (porcellanite) to chert (quartz). Reprecipitation of silica as cement would explain the increased strength of the sedimentary framework that is indicated by the increase in sonic velocity.

The lower reflector appears to be the interference of a negative impedance contrast at $1020 \mathrm{~m}$ (603B-21-6/ 603B-22-1) and of the tail of the reflection from the upper reflector. The top of physical properties Subunit 8a, $1020 \mathrm{~m}$, is characterized by a sharp rise in grain density, which is more than offset by a fall in porosity, because the polarity of reflection is governed by the fact that the lower porosity causes velocity to fall. The low velocities recorded were partly due to (1) the friable state of the samples, which hindered measurement because only a poor acoustic couple could be achieved, and (2) the large amounts of gas that Core 603B-22, containing green claystone, exsolved, increasing the likelihood of damage to the sedimentary fabric. The negative impedance break at $1020 \mathrm{~m}$ coincides with the boundary between lithologic Units II and III (radiolarian claystone above variegated claystone). The decrease in biogenic silica is correlated with a decrease in the sonic velocity as a result of the comparatively retarded diagenesis.

Lack of data for two sections within physical properties Unit 7 is unfortunate, but it seems unlikely that any significant boundaries have been missed. Cores 603B-15 through 603B-29 are barren of microfossils, making any chronostratigraphy unreliable. A study of sedimentation rates indicates that there is at least one unconformity within the interval and that the sedimentation rate is significantly lower (see Biostratigraphy section of the site chapter). The upper horizon may then equate with Horizon $\mathrm{A}^{\mathrm{u}}$, which is widespread along the continental margin of the North American Basin and is attributed to increased contour-current activity during late Eocene to early Miocene times (Tucholke, 1981). The lower horizon poses greater problems of correlation. It marks a rise in the CCD, concurrent with an increase in biogenic silica to a dominant position (consistent with the lower sedimentation rate). Elsewhere in the North American Basin, a similar event is thought to be responsible for producing a chert-rich horizon of middle Eocene age, which is accepted as the lithological correlation of Horizon $\mathrm{A}^{\mathrm{c}}$. Strictly speaking, Horizon $\mathrm{A}^{\mathrm{c}}$ is the top of this chert-rich layer, suggesting that it coincides with the upper horizon - the lower horizon has no seismostratigraphic name. The absence of cherts make the name "Horizon $\mathrm{A}^{\mathrm{c}}$ " inappropriate: they are absent either because diagenesis has not proceeded far enough (for whatever reason, the silica concentration was insufficient) or because they were removed by bottom currents when Horizon $A^{u}$ was eroded. Similarly, the names Horizons $\mathrm{A}^{\mathrm{t}}$ and $\mathrm{A}^{*}$ are unsuitable because significant turbidites or lithified limestones, respectively, are absent. (The upper and lower horizons are labeled $\mathrm{A}^{\mathrm{u}} / \mathrm{A}^{\mathrm{t}}$ and $\mathrm{A}^{\mathrm{c}} / \mathrm{A}^{*}$ in the site chapter. These names have not been used in this chapter, for the reasons just noted.)

\section{Horizon X}

Horizon $\mathrm{X}$ is correlated with $700 \mathrm{~m}$ (Section 603-42-2). There is some uncertainty in interpreting it on the profile near Site 603 , as earlier noted, and other correlations would obviously yield different interpretations (Fig. 5). Horizon $\mathrm{X}$ is correlated with the top of physical properties Subunit $5 \mathrm{a}$, which is defined by a downward increase in velocity and a low carbonate content. This corresponds to the top of lithologic Subunit IC, which is characterized by the appearance of biogenic silica. The lower bulk density is caused by a decrease in grain density combined with an increase in porosity. Higher velocity and low porosity indicate that, for some reason, the sedimentary framework is better cemented and more important for sound transmission.

\section{Upper Interval Reflectors}

Horizon M2 is correlated with $563 \mathrm{~m}$ (Core 603-27). This is the largest of a number of physical properties breaks between $510 \mathrm{~m}$ and $617 \mathrm{~m}$, all of low amplitude. Velocity increases markedly, and grain density and porosity both contribute to a local lowering of bulk density. Horizon M2 is correlated with Horizon X of Site 388 , which is attributed to an increase in the stiffness of hemipelagic clays (Benson, Sheridan, et al., 1978; van Hinte, personal communication, 1984). The change in grain density suggests that compositional change is also a factor at Site 603: Site 388 shows no comparable change in grain density. The higher carbonate content is attributed to siderite nodules, burrows, and layers; the greater velocity of siderite contributes only a small amount to the overall velocity rise, the balance being due to variation in the degree of diagenesis. The density break is more gradual, suggesting that energy is returned from a 
slightly more expanded interval of sediments between 547 and $575 \mathrm{~m}$.

Horizon M1 does not correlate well with the preferred model (Model 6). It is difficult to trace on the profile and is particularly weak at Site 603 . However, the broad reflector immediately preceding Horizon M1 does match closely. This correlates with $366 \mathrm{~m}$ (Section 603-16-3), the top of physical properties Subunit 3a. Both sonic velocity and bulk density increase at this depth. Similarly, the immediately succeeding white loop matches and correlates with the base of lithologic Subunit IA at $448 \mathrm{~m}$ (Sample 603-19,CC), the top of physical properties Subunit 3 b. Here, nannofossil-bearing clay/claystone overlies quartz-mica-bearing claystone, and sonic velocity decreases; no clear trend is visible in other properties.

Horizon P does not correlate well with Model 6. Again, it is low in amplitude and difficult to trace locally. It appears to correlate with $190 \mathrm{~m}$ (Section 603C-22-4), the top of physical properties Subunit 2c, which is defined by a rise in shear strength. No abrupt variation is shown by other properties.

Horizon M2 marks the top of a sequence of strong reflectors (seismic Subunit 2d of site report). The seismic units above horizon M1 (seismic Subunits 2a and $2 \mathrm{~b})$ are characterized by migrating wave patterns which "appear to be formed by current action in deep water" (Benson, Sheridan, et al., 1978). They are large-scale features on the order of $3 \mathrm{~km}$ wavelength and $75 \mathrm{~m}$ amplitude. Their subsurface seismic expression, although of low acoustic amplitude, clearly shows them to be laterally and vertically persistent. It can be assumed that this expression is due to small, systematic changes in the physical properties of the sediments; it therefore should be discernible from the measurements taken. The seismic unit is entirely within lithologic Unit I, hemipelagic claystone. The recovered sediments are much disturbed by drilling in Hole 603; Hole 603B was washed through this interval. Thus Hole $603 \mathrm{C}$ provided the best chance to gain reasonable recovery of the upper $360 \mathrm{~m}$.

None of the breaks picked from the data for Hole $603 \mathrm{C}$ are particularly striking, as might be expected from the low amplitude of reflections from the unit. The predominant trend is dewatering: porosity, water content, and bulk density show a very even trend. Variation in the measured velocity may be explained by disturbance of the sample and poor signal propagation resulting from high attenuation and the presence of gas. Shear strength and carbonate content are the most reliable properties. Composition is unlikely to be affected; shear strength, being directly related to the ability of a sediment to resist deformation, may still be expected to show the breaks. (Grain size analysis would also be relevant, but no data were available.) On the basis of shear strength and carbonate content, seven minor breaks can be identified.

The comparison between the synthetic seismogram and the profile is nowhere near so good as for the lower formations, but in such a sequence of dipping reflectors any errors in the positioning of the hole to one side of the seismic profile will obviously degrade the correlation. (Also, if the absolute error remains the same, then as the amplitude decreases, the percentage error must increase.) The lack of a precise velocity function over this interval, $0-554 \mathrm{~m}$, is a further source of error. So, although precision in the timing of breaks and their relative amplitude is poor, the causes for the breaks appear valid and may be due to minor changes in the depositional process. The number of breaks identified is sufficient to produce all the reflections at the frequencies used.

The percentage of carbonate has been related to climate (Mayer, 1979), and changes in shear strength may be related to changes in the depositional rate, which in turn is related to the intensity of bottom current activity and to climate (Jones et al., 1970). The high terrestrial content of the sediments at Site 603 may obscure the climatic signal, but since climatic processes may affect physical properties, reflectors caused by variations in physical properties may still be attributed to climatic factors. If climate is important, then it seems likely that the variation is of a spatial frequency considerably higher than either that of the site survey seismic profiling or the measurements taken from the recovered core. More detailed work is needed to confirm this hypothesis.

\section{PHYSICAL PROPERTIES MODELING, SITE 604}

At Site 604 drilling penetrated approximately $290 \mathrm{~m}$ into Quaternary and Neogene sediments but encountered no significant regional reflectors. Accurate correlation with the seismic profile (U.S.G.S. line 25, Fig. 9) is hindered by the absence of wireline logs and the amount of offset from the line of section. Four velocity functions have been examined: the first is from sonobuoy data (Houtz, 1973), the second is the stacking velocity determined during processing of the seismic line, and the third and fourth are determined from correction of the physical properties of recovered core measured in the shipboard laboratory, with and without mud correction for unrecovered material. Again a physical properties stratigraphy was used (Fig. 10). All models give two-way traveltimes between events which match to within $2 \mathrm{~ms}$ for events below $151 \mathrm{~m}$ (see Table 3). There is a large disparity in the initial transit time, although below $150 \mathrm{~m}$ the models agree well with each other. In particular, the mud-corrected physical properties model and the semblance analysis model (Models 2 and 4, Fig. 11) compare very closely over the interval $151 \mathrm{~m}$ to total depth (295 m), even for the interval of low recovery (212-235 m). The top interval velocity is overestimated (there are no data for the uppermost sediments, which were not recovered).

In interpreting the seismic section at Site 604, care is needed in assessing the most important reflectors. The problem of modeling the velocity of sediments immediately below the seabed suggests that the site location is out of the plane of the section. Therefore, only those reflectors which are laterally continuous are likely to be seen at the site, and these are not necessarily the events of highest amplitude. The scale of Figure 11 is insufficient to show lateral continuity, and careful comparison with the more complete section (Fig. 9) is advisable prior to interpretation. In particular, the events at 3.34 , 3.41 , and $3.45 \mathrm{~s}$ appear to be more important than the higher-amplitude events at 3.30 and $3.48 \mathrm{~s}$ (TWT). 




Figure 9. U.S.G.S. line 25, site survey profile for New Jersey Transect Sites 604 and 605.

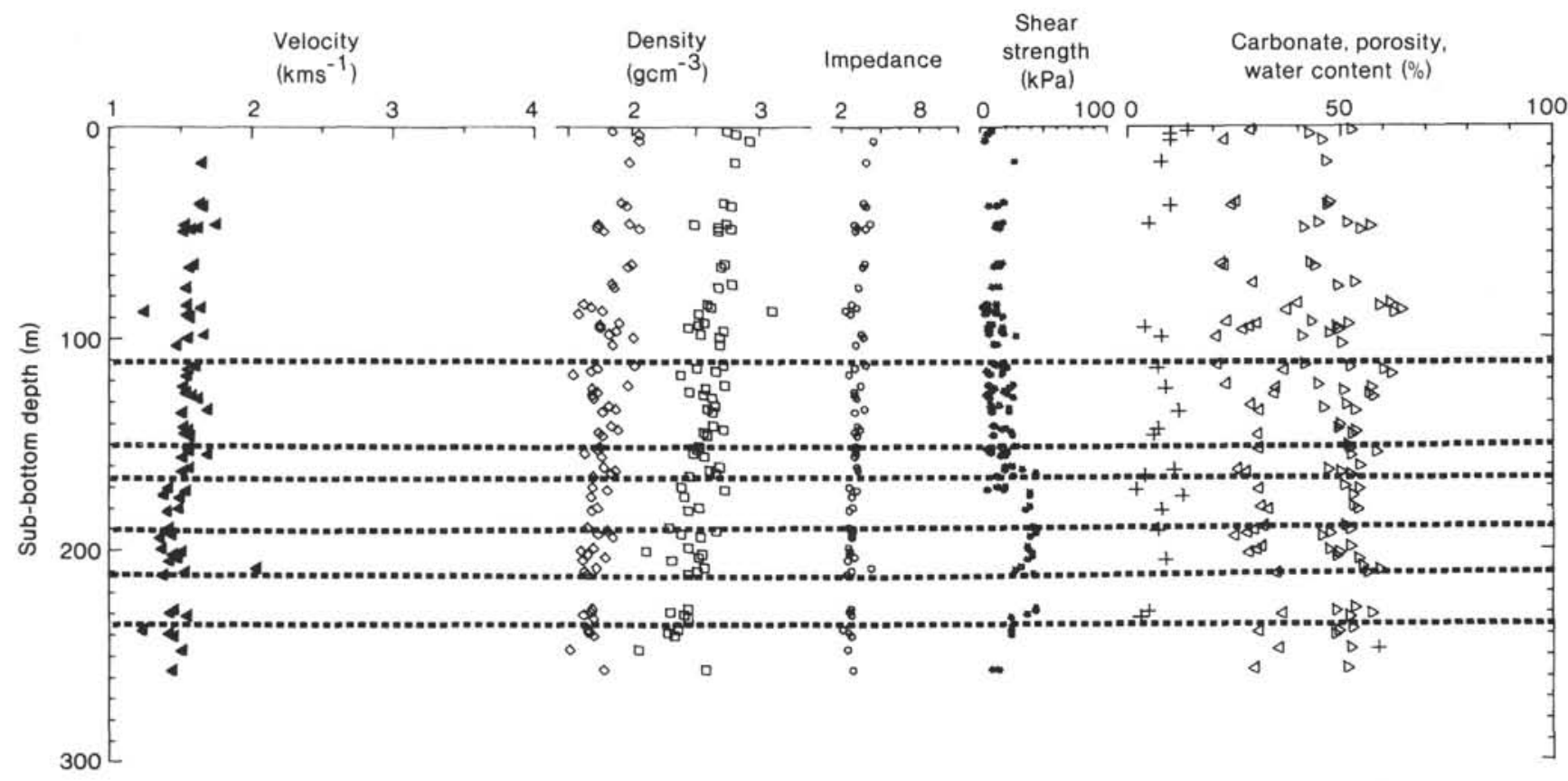
- Horizontal velocity
ㅁ Grain density
+ Carbonate content
- Vertical velocity
- Impedance
$\triangleright$ Porosity
$\diamond$ Wet-bulk density
* Shear strength
$\triangleleft$ Water content

Figure 10 . Summary of physical properties for Site 604 , including the physical properties stratigraphy. 
Table 3. Comparison of modeled interval transit times (from seafloor), Site 604.

\begin{tabular}{|c|c|c|c|c|c|c|c|}
\hline \multicolumn{2}{|c|}{$\begin{array}{l}\text { Model 1: } \\
\text { Houtz }\end{array}$} & \multicolumn{2}{|c|}{$\begin{array}{l}\text { Model 2: } \\
\text { Semblance } \\
\text { study }\end{array}$} & \multicolumn{2}{|c|}{$\begin{array}{l}\text { Model 3: } \\
\text { Phys. } \\
\text { Props. }\end{array}$} & \multicolumn{2}{|c|}{$\begin{array}{l}\text { Model 4: } \\
\text { Phys. Props. } \\
+ \text { mud corr. }\end{array}$} \\
\hline & $d t$ & & $d t$ & & $d t$ & & $d t$ \\
\hline 0.138 & & 0.157 & & 0.122 & & 0.133 & \\
\hline 0.184 & 46 & 0.207 & 50 & & 42 & 0.176 & 43 \\
\hline 0.198 & 14 & 0.220 & 13 & 0.176 & 12 & 0.189 & 13 \\
\hline 0.212 & 14 & 0.231 & 11 & 0.188 & 12 & 0.201 & 12 \\
\hline 0.230 & 18 & 0.249 & 18 & 0.205 & 17 & 0.220 & 19 \\
\hline 0.256 & 26 & 0.274 & $\begin{array}{l}25 \\
26\end{array}$ & 0.228 & 23 & 0.244 & 24 \\
\hline $\begin{array}{l}0.282 \\
\text { T.D. }\end{array}$ & & 0.300 & & $\begin{array}{l}0.252 \\
0.313\end{array}$ & & $\begin{array}{l}0.271 \\
0.338\end{array}$ & \\
\hline
\end{tabular}

Note: $d t=$ interval transit time.

The hole bottomed in a Miocene debris flow which appears to have a top seismic expression at $3.45 \mathrm{~s}$ (TWT). This would then correlate with the lithologic Unit III/ Unit IV boundary at $238 \mathrm{~m}$ sub-bottom.

If the models are given a static correction to compensate for the lack of modeling data at the top of the hole and aligned at $3.45 \mathrm{~s}$ (TWT), then Model 2 gives the best fit (Fig. 11). If the misfit at the seabed is accepted, the high-amplitude reflector at $3.30 \mathrm{~s}$ (TWT) is close to the boundary between physical properties Subunits 3a and $3 \mathrm{~b}, 122 \mathrm{~m}$. The reflector at $3.34 \mathrm{~s}$ (TWT) correlates with $151 \mathrm{~m}$ (sub-bottom) within physical properties Subunit $3 \mathrm{~b}$. If other models are used, these interpretations will obviously differ.

Again, we are making an assumption about the correlation before doing the modeling, implying, in this case, that we know where the top of lithologic Unit IV is in order to make a correlation at other depths. With the available data, any amount of modeling is going to be imprecise, primarily because all the physical property breaks are of particularly low amplitude. This study at Site 604 is a good illustration of the difficulties of modeling and interpretation. The velocity function need only be varied slightly in order to alter the exact correlation. The fact that we are working on dipping strata increases the need for accurate positioning: for example, the problem of a misfit at the seabed is removed by picking the site location $1 \mathrm{~km}$ to the southeast, although this is unlikely. In such a case, modeling only supplies constraints on any interpretation.

\section{PHYSICAL PROPERTIES MODELING, SITE 605}

Five models have been constructed in an attempt to determine the velocity function at Site 605 . The same stratigraphy has been used in each model; it is based on discontinuities in the physical properties of samples as measured aboard ship (Fig. 12). The first is based on Houtz's (1973) velocity function deduced from sonobuoy data. A second uses the semblance data obtained from stacking of U.S.G.S. line 25 . Models 3 and 4 use aver-

NW

$$
0 \quad \text { m } 500
$$

SE

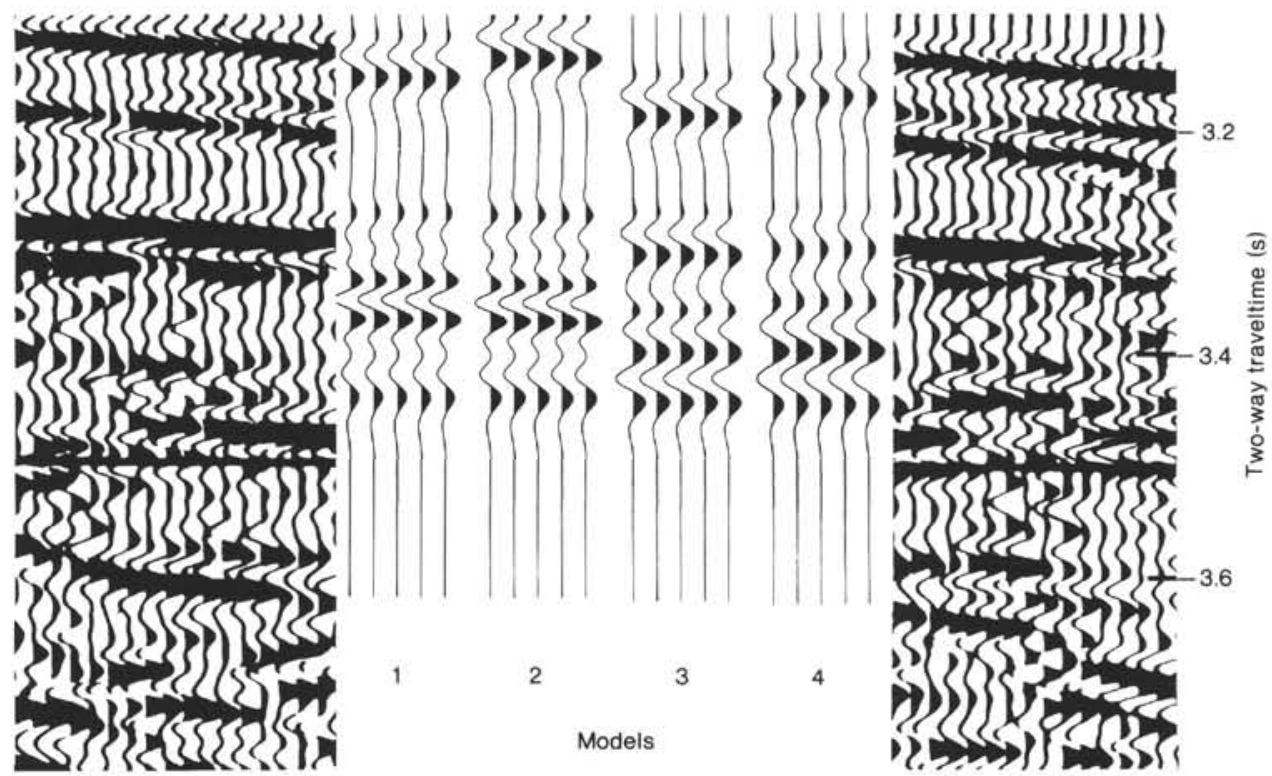

Figure 11. Comparison of models at Site 604. The models have been inserted at the site location and differ primarily in the velocity function used in their construction. 1. Velocity function from Houtz (1973). 2. Velocity function from stacking velocities used in the processing of U.S.G.S. line 25.3 . Velocity derived from corrected physical properties. 4 . Model 3 with correction for poor recovery. All models appear to overestimate the velocity through the uppermost sediments. They are displayed with a static correction that shows the most likely correlation. High amplitude is a misleading guide to the lateral persistence of reflectors and thus to their stratigraphic importance. 


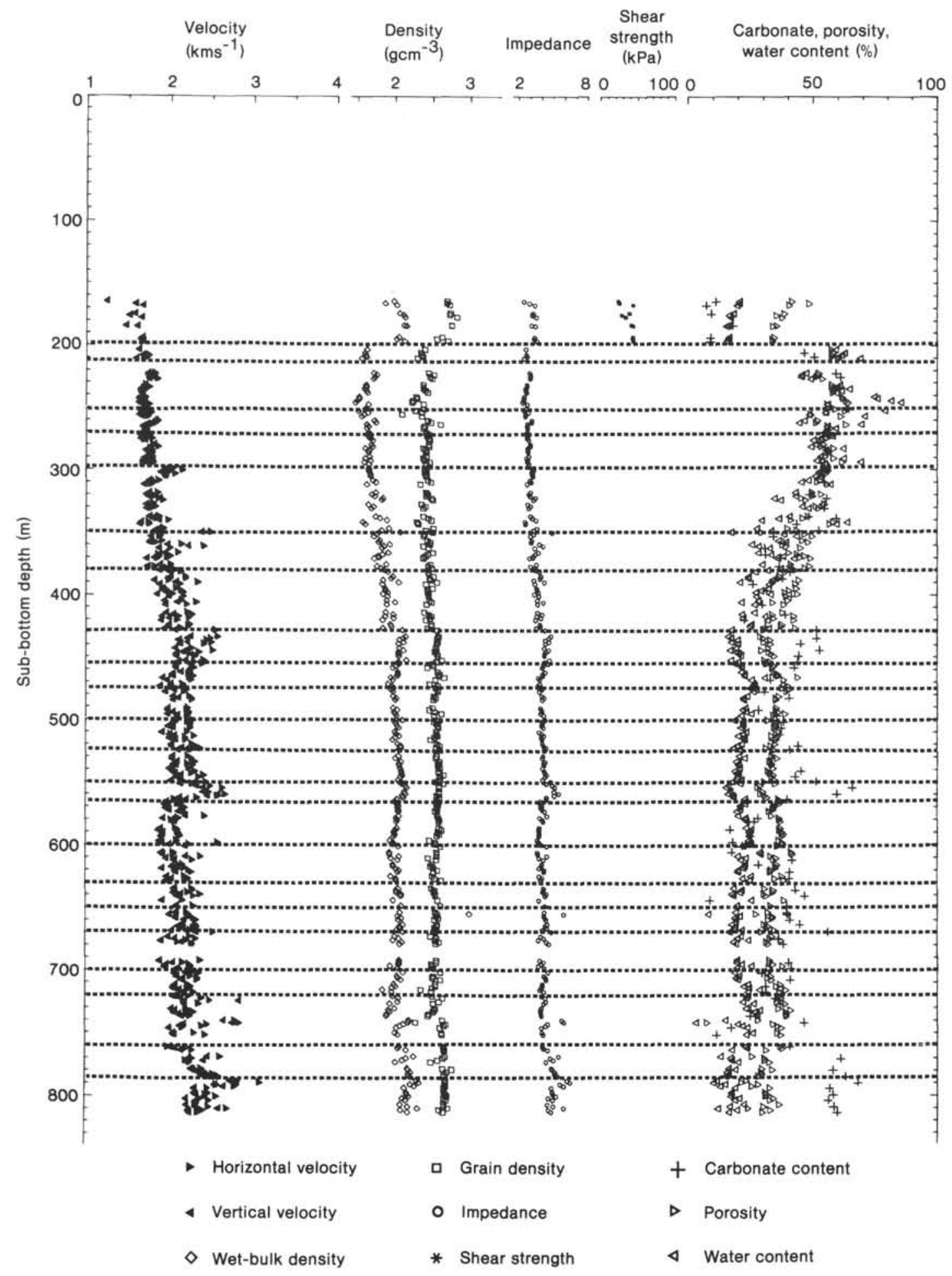

Figure 12. Summary of physical properties for Site 605 , including the physical properties stratigraphy.

aged corrected physical property data as described above; Model 4 includes the mud correction for unrecovered material. Various shortcomings of this third modeling scheme are apparent from this study, and their correction yields a fifth model. The inaccuracy of the interpretation based on the semblance data should be remembered when considering other models based on these ve- locities. Model $4 / 5$ has been used for interpretation of lithology (Fig. 13).

The first problem is to interpret the section: even tracing Horizon $\mathrm{A}^{\mathrm{u}}$ is difficult on U.S.G.S. Line 25 (Fig. 9). The high-amplitude reflection at $0.17 \mathrm{~s}$ below seafloor at Site 604 onlaps onto the erosional surface that is Horizon $\mathrm{A}^{\mathrm{u}}$ just downslope of Site 605 , causing polarity re- 


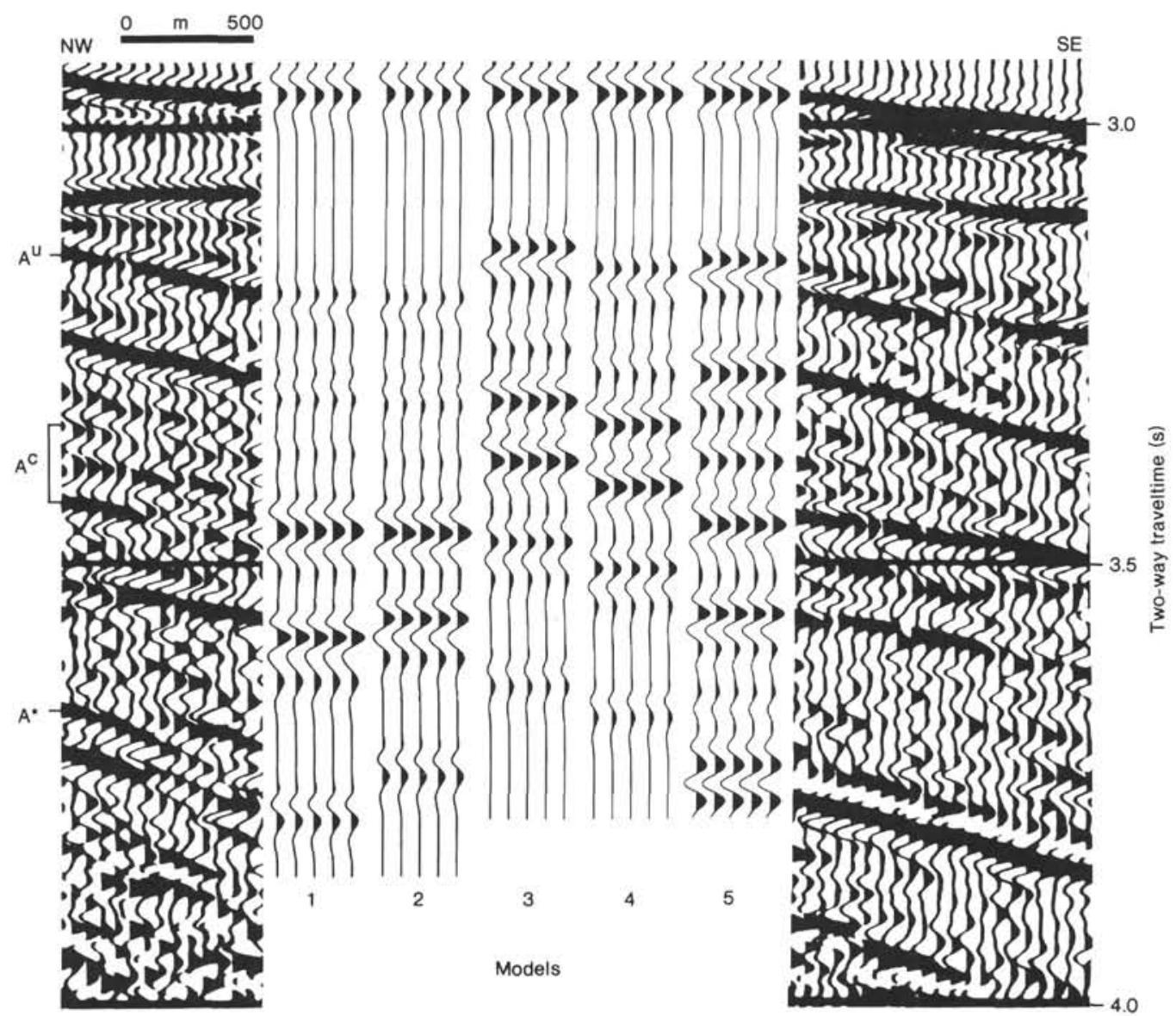

Figure 13. Comparison of models at Site 605 , with models inserted at the site location. They differ primarily in the velocity function used in their construction. 1. Velocity function from Houtz, 1973. 2. Velocity function from stacking velocities used in the processing of U.S.G.S. line 25 . 3. Velocity derived from corrected physical properties. 4 . Model 3 with correction for poor recovery. 5 . Model 3 with correction for reflectors not shown by significant porosity variation.

versal. Horizon $\mathrm{A}^{\mathrm{u}}$ is faulted upslope from Site 605. The preferred interpretation correlates a strong black loop with the unconformity (Fig. 13). An unconformity of the appropriate age and duration was encountered at $203 \mathrm{~m}$ sub-bottom at Site 605 ; it is the boundary between lithologic Units I and II and correlates with the reflector. These are strongly contrasting lithologies of gray silt-rich clay (Unit I) and greenish gray biogenic-silica-rich nannofossil chalk (Unit II). There are no data for the interval from 198-203 m; the thickness of lithologic Subunit IB is insignificant with respect to the resolution of seismic imaging. Therefore, it is valid to model the Horizon $\mathrm{A}^{\mathrm{u}}$ unconformity as one strong reflection coefficient. The polarity is negative: although the break is marked by a rise in velocity, there is an even greater drop in bulk density. The change in lithology is most pronounced on the porosity and density logs and, in consequence, gives a strong reflection in Models 3-5 (the physical properties modeling scheme is based on porosity data).

\section{Upper Section at Site $605(0-350 \mathrm{~m})$}

The upper sediment velocities of Sites 604 and 605 as calculated from semblance study of multichannel data are very different (see Table 4). It seems likely that the top interval velocity of Site 605 is overestimated; it should be closer to that of Site 604 . It should be remembered that the most difficult interval to model is the uppermost one extending down from the seafloor, because the velocity is so variable. A further source of modeling error at Sites 604 and 605 results from the empirical velocity/porosity relationship used to correct to in situ val-

Table 4. Comparison of semblance data from Sites 604 and 605 , New Jersey Transect.

\begin{tabular}{|c|c|c|c|c|c|c|c|}
\hline \multirow[b]{2}{*}{ TwT } & \multicolumn{3}{|c|}{ Site 604} & \multicolumn{4}{|c|}{ Site 605} \\
\hline & $\mathrm{V} / \mathrm{rms}$ & $\mathrm{V} /$ int & depth & TWT t & $\mathrm{V} / \mathrm{rms}$ & $\mathrm{V} /$ int & depth \\
\hline 0 & 1516 & 1518 & SL & 0 & 1516 & 1521 & $\mathrm{SL}$ \\
\hline 3.166 & 1518 & 1427 & SB & 2.950 & 1512 & 1617 & SB \\
\hline 3.355 & 1513 & 1821 & 135 & 3.212 & 1529 & 1733 & 212 \\
\hline 3.697 & 1544 & 2373 & 446 & 3.417 & 1542 & 2376 & 390 \\
\hline 4.464 & 1715 & & 1356 & 4.125 & 1714 & & 1231 \\
\hline
\end{tabular}

Note: Velocities in m/s, TST is two-way traveltime (s), depths in meters. $\mathrm{V} / \mathrm{rms}=$ root mean squared velocity, $\mathrm{V} / \mathrm{int}=$ interval velocity. $\mathrm{SL}=$ sea level, $\mathrm{SB}=$ seabed. 
ues. This was based on data recovered at Site 603 because accurate determination of the functions relating physical properties parameters requires a larger data set than is available at Sites 604 and 605 . The function determined at Site 603 was used even though the lithology at Site 603 is considerably more clastic than the chalks found at the New Jersey Transect sites.

The interval from $203-270 \mathrm{~m}$, corresponding to the uppermost chalk, is distinguished by negligible separation of vertical and horizontal velocities. This low acoustic anisotropy shows that the sediments have undergone minimal diagenesis. Absence of cementation makes them more prone to drilling disturbance and the effects of pressure reduction. Porosity rebound has been corrected, but given the very high porosity of this formation there may still be a significant error that will be compounded when the value is used for velocity and density correction. The break at $250 \mathrm{~m}$ appears to be more important than the measured values indicate. It correlates with a very strong event at $3.28 \mathrm{~s}$ (TWT).

The physical properties break at $260 \mathrm{~m}$ is defined by an increase in velocity and wet-bulk density which persists for only two sections $(3 \mathrm{~m})$. Grain density does not change, suggesting that packing and cementation are responsible for the change. Porosity is lower for these two sections, in contrast with the scattered values from the interval immediately above.

If the assumptions concerning the upper part of the model are correct then the fit between model and profile from $270 \mathrm{~m}$ down to total depth $(815 \mathrm{~m})$ is reasonable (Fig. 13). The break at $270 \mathrm{~m}$ suffers from interference with the bright reflection at $250-260 \mathrm{~m}$ and thus shows as a white loop at $3.30 \mathrm{~s}$ (TWT), (Fig. 13). It occurs within lithologic Unit II and is created by a slight reduction (downward) in impedance following the sharp rise at $250 \mathrm{~m}$, corresponding to Core $605-14$, which was lithologically indistinguishable from adjacent cores, suggesting that it may not be appropriate to delineate a break at this depth.

The break at $293 \mathrm{~m}$ is very marked on the velocity $\log$, but is not seen in any other properties. The bulk density measurements for the interval 299-308 m (Core 17) display a consistency that is not repeated until compared with measurements from below $428 \mathrm{~m}$ (top of physical properties Unit 6), which have undergone considerable diagenesis. The lack of expression in the porosity log means that no significant reflection will be produced by the modeling scheme (see above). There is little doubt that there exists a layer about $10 \mathrm{~m}$ thick which exhibits an advanced state of diagenesis compared to adjacent strata. Opal-A is tey ton sah sisenegaid acilllica diagenesis has not yet begun because the depth of burial is insufficient.

\section{Horizon $\mathbf{A}^{\mathbf{c}}$}

The next break in the physical properties is seen at $350 \mathrm{~m}$. Both horizontal and vertical velocities increase, and the sediments become acoustically anisotropic, indicating the development of a framework structure. In contrast, the bulk density values below $350 \mathrm{~m}$ exhibit considerable scatter. This might be due to compositional variation, but the grain density shows less variation than might be expected were this the case. For reasons that are not clear, the bulk gravimetric measurements for this interval (350-380 m) are variable. This break is responsible for an event of medium amplitude which matches well with a discontinuous reflector at $3.32 \mathrm{~s}$ (TWT).

Horizon $\mathrm{A}^{\mathrm{c}}$ was encountered at Site 612 (Leg 95), some $16 \mathrm{~km}$ upslope from Site 605 . Wilkens et al. (in press) have demonstrated a clear diagenetic boundary, characterized by a large reduction in porosity (on the order of $60 \%$ down to $40 \%$ ) and caused by the mobilization of silica, which reprecipitates, replacing carbonate clasts such as foraminifer tests with lepispheres of opal-CT (Weaver and Wise, 1974). Thus, Horizon $\mathrm{A}^{\mathrm{c}}$ is well defined at Site 612 at $324 \mathrm{~m}$ sub-bottom (Wilkens, pers. comm., 1984).

This horizon was traced on the site survey profile to Site 605. The correlation crosses several faults and is further complicated by the dipwise thinning of reflectors downslope midway between the two sites; here, correlation is drawn at a tenuous surface of truncation and onlap. At Site 605 this horizon is located at $350 \mathrm{~m}$ sub-bottom, the depth identified as Horizon $\mathrm{A}^{\mathrm{c}}$ by the Leg 93 shipboard sedimentologists, who based their interpretation on the presence of opal-CT. This diagenetic horizon coincides at 605 with a minor compositional change, demonstrated by the change in carbonate content from approximately $50 \%$ above $350 \mathrm{~m}$ to around $33 \%$ below. It should be emphasized that this is by no means a major reflector at Site 605, and its correlation with Horizon $\mathrm{A}^{\mathrm{c}}$ at Site 612 is far from certain. If erosion has occurred at the site, then Horizon $\mathrm{A}^{\mathrm{c}}$ proper may have been removed, or possibly the components necessary for its diagenetic formation were never deposited. Nevertheless, the fact that both the correlation traced from Site 612 and this modeling provide independent interpretations strengthens the confidence in the correlation at Site 605.

At $380 \mathrm{~m}$ velocity increases and bulk density becomes less variable. No change is seen in grain density, suggesting that the change is due to further cementation of the framework. The reflection produced is low in amplitude and appears to be truncated a few kilometers downslope by the surface identified as Horizon $\mathrm{A}^{\mathrm{c}}$.

The next break in the physical properties, $428 \mathrm{~m}$, is one of the three strongest breaks at the site. It is clearly seen as a change in grain density (increase downward) and a reduction in porosity. Bulk density and velocity also increase. The scatter of bulk gravimetric measurements is much reduced, indicating a significant increase in diagenesis. The rise in grain density indicates compositional change, in agreement with the carbonate content, which shows a significant increase from approximately 30 to $50 \%$. No change in lithology corresponds to the physical properties change-the break lies roughly in the middle of Unit III. There is no evidence of onlap/truncation on the profile (indeed, this surface is truncated downslope by the surface termed Horizon $\mathrm{A}^{\mathrm{c}}$ ).

At Site 612 , the sedimentological horizon identified with $\mathrm{A}^{\mathrm{c}}$ was coincident with a physical properties break defined by a reduction in porosity from approximately 60 to $40 \%$ in response to silica mobilization (Wilkens, 
pers. comm., 1984). A very similar signature is seen at $428 \mathrm{~m}$ on the porosity log from Site 605 ; it correlates with a reflector of similarly high amplitude. On the basis of physical properties alone, Horizon $\mathrm{A}^{\mathrm{c}}$ at Site 605 would be located at this depth, some $78 \mathrm{~m}$ below where it is placed. At Site 612 the age of Cores 35 and 36 (309$338 \mathrm{~m}$ ) is middle Eocene, which compares more favorably with the lower-middle Eocene age of Core 605-22 (346-356 m). Thus, the reflector as traced appears to be synchronous (given the resolution of palaeontological zonation). In contrast, the high-amplitude event, which would have been traced with a profiling system of lower quality than the 12 -fold U.S.G.S. line and which corresponds to the strong physical properties unit boundary, is diachronous.

The velocity data show that anisotropy increases strongly at $428 \mathrm{~m}$, coinciding with an increase in the sonic velocity. The values decrease downward slightly over the next $30 \mathrm{~m}$ and then show a further negative break at about $455 \mathrm{~m}$. This trend is also seen on the porosity log, which produces a medium-amplitude, negative coefficient on the physical properties model. This is a broad white loop immediately succeeding the strong black reflection from $428 \mathrm{~m}$ and matches the profile well (Fig. 13). Again, this is entirely within lithologic Unit III.

\section{Events below Horizon $\mathbf{A}^{\mathrm{c}}$}

A series of low-amplitude events at $475 \mathrm{~m}, 500 \mathrm{~m}$, and $525 \mathrm{~m}$ appear to interfere, thus producing the acoustically quiet interval between $0.564 \mathrm{~s}$ and $0.615 \mathrm{~s}$ subbottom. These breaks are arbitrarily chosen to permit more continuous modeling - they do not correspond to breaks in the physical properties and are effectively ignored by the modeling scheme. Lithologically, all are within Unit III, a monotonous sequence of nannofossil limestones and chalks. The evidence for cyclicity seen in the cores is not discernible from the physical properties, although cyclicity may explain the acoustic character of the interval, which tends toward the random or chaotic downslope (thickening cycles interfering differently).

High-amplitude physical property breaks at 552 and $565 \mathrm{~m}$, which bound physical properties Unit 8, are together responsible for the next strong reflector. This has no name, although it has been suggested that it correlates with the $52 \mathrm{Ma}$ hiatus of Vail et al. (1980) (van Hinte, personal communication, 1984). The evidence of onlap above this horizon is ambiguous. The break is produced by an abrupt downward decrease in sonic velocity and wet-bulk density. Porosity is reduced and carbonate content is elevated to around $60 \%$. The top of lithologic Unit IV at $565 \mathrm{~m}$ represents the sharp contact between the light greenish nannofossil limestone and the underlying dark clayey nannofossil limestone (marl) (Sites 604 and 605 lithology section, site chapter, this volume). If the physical properties breaks are considered as the source of a pair of reflections emanating from the top and bottom of physical properties Unit 8, the distance between them is close to the optimum for constructive interference between the individual reflections $(45 \mathrm{~Hz})$. The lower, negative reflection is the stronger, which ex- plains the negative polarity of their combined strong reflector at $0.608 \mathrm{~s}$ sub-bottom. The model does not compare particularly well in the transit time to this horizon and suggests that the interval velocity between $428 \mathrm{~m}$ and $565 \mathrm{~m}$ is overestimated-the model gives $0.109 \mathrm{~s}$ $(2.514 \mathrm{~km} / \mathrm{s})$, whereas the profile indicates a transit time of $0.135 \mathrm{~s}(2.030 \mathrm{~km} / \mathrm{s})$, assuming the correlations are correct. The stacking velocity suggests that the actual interval velocity lies somewhat between these two values; Model 5 has been corrected at this level.

Between $600 \mathrm{~m}$ and $720 \mathrm{~m}$ there are a number of lowamplitude reflections, which correspond to the acoustically quiet interval between $3.57 \mathrm{~s}$ and $3.75 \mathrm{~s}$ (TWT). Below $663 \mathrm{~m}$, carbonate diagenesis is advanced enough to have caused recrystallization of most biogenic fragments.

At 760 and $785 \mathrm{~m}$, important breaks occur in the physical properties, particularly from bulk density and velocity data. The modeling scheme fails to give high values to the coefficients at these depths, simply because the porosity log does not show an equivalent variation. This demonstrates a lower limit to the applicability of the modeling scheme, which is based primarily on porosity. Once porosity is much reduced, variation is less sensitive and no reflections can be modeled. Model 5 has been corrected using velocity data to adjust amplitude, although the timing has not been altered.

The top of lithologic Unit V at $740 \mathrm{~m}$ is characterized by an abundance of foraminifers and terrigenous silt. The uppermost $6 \mathrm{~m}$ of Subunit VA is a unique interval in which the silt and clay content decreases rapidly upward, distinct, dark, filled burrows vanish, and the lithology becomes a very dense, light greenish grey limestone almost $99 \%$ carbonate (Sites 604 and 605 site chapter, this volume). The uppermost $7 \mathrm{~cm}$ of this limestone is noted as an unconformity in the sedimentology report. This group of reflectors roughly correlates with Horizon $\mathrm{A}^{\mathrm{c}}$ of Klitgord and Grow (1980). The seismic stratigraphy for the Sites 604 and 605 (this volume) positions Horizon $\mathrm{A}^{\mathrm{c}}$ somewhat higher and names this lower strong reflector "Horizon $\mathrm{A}^{*}$." Horizon $\mathrm{A}^{*}$ is a regional reflector in the North American Basin; it is considered to mark the top of a particularly well lithified limestone of Maestrichtian age (Tucholke et al., 1977). Vail et al. (1980) consider Horizon $A^{*}$ to be Thanetian in age, and it has been equated with Horizon $A^{52}$ (van Hinte, personal communication, 1984).

The bulk density change is more noticeable at $740 \mathrm{~m}$; density is particularly variable throughout lithologic Unit V. The uppermost $6 \mathrm{~m}$ of Subunit VA exhibits high velocity, but the main rise in velocity does not occur until $760 \mathrm{~m}$, coinciding with the rise in carbonate content. Another thin, high-velocity stratum at $786-791 \mathrm{~m}$ (Sections 605-69-1 to 605-69-2) further complicates the pattern of interfering reflections.

The strong reflectors at $0.775 \mathrm{~s}$ TWT (below seafloor) (white loop) and $0.792 \mathrm{~s}$ (black loop) on the profile are the product of these closely spaced impedance contrasts. The suggestion that $740 \mathrm{~m}$ may be an unconformity is not supported by the seismic profile, as only the very va- 
guest onlap is discernible and there is no sign of truncation. If the modeling is accurate, then the boundary between Unit IV and Unit V can be drawn at $3.72 \mathrm{~s}$ (TWT).

\section{CONCLUSIONS}

The division of the sedimentary column into physical properties units which average $40 \mathrm{~m}$ thickness (i.e., four cores per division) implies a degree of precision that is unjustified if judged by the demands of sampling theory (two samples per wavelength). The whole core represents a much larger sample and provides information for the intervals between the physical property measurements. Care has been taken to be objective in synthesizing the physical properties data into a seismogram. The method clearly shows that the given number of reflecting boundaries of approximate amplitude and polarity are completely sufficient to produce all but the weakest reflectors as seen by the respective site survey profiles (at the given frequencies).

The method devised for this study following Shipley (1983) is more objective than the preceding in its calculation of the all-important velocity function. The evaluation of amplitude and sign of reflection coefficient by this scheme results in fewer negative-polarity reflectors and more realistic relative amplitudes, particularly for the upper reflectors at Site 603 (Horizons P, M1 and M2). There still remains the subjective process of subdividing sediments using recognized breaks in the various properties measured. Although this must affect the final result, it is interesting to note that several recognized breaks were effectively ignored by the correction/averaging algorithm, because insufficient contrast remained after calculating the properties of two adjacent units (e.g., $235 \mathrm{~m}$, Site 603). The dependency on porosity data to supply the correction is relevant for the realm of initial diagenesis. Although the velocity function remains accurate at reduced porosities, its sensitivity is no longer sufficient to model reflectors.

Reflectors sampled at Sites 603 and 605 demonstrate the sensitivity of acoustic reflection to very small changes in the degree of diagenesis. Slight compositional changes permit different stages of diagenesis to be reached as different constituent minerals become mobile at different depths. Perhaps the most important of these is the nature of the grain-to-grain contact, which is affected by consolidation and the development of a cement. Horizon $\mathrm{A}$ and Horizon $\mathrm{X}$ at Site 603 and Horizon $\mathrm{A}^{\mathrm{c}}$ at Site 605 both appear to result from increased silica content; elevated velocity and low porosity indicate an increase in the strength of the sediment framework as a result of the early formation of a cement.

At Site 603 there is a noticeable difference in the character of the main reflectors below the Horizon A complex compared with those above (including Horizon A). The more advanced state of diagenesis of the lower sediments produces significantly higher transmission velocities. On a time section, this has the effect of "squeezing" each unit so that interference between individual reflections is much more important. The homogeneity of the upper sediments at the site increases this contrast.
Abrupt lithological changes are more important, in terms of the amplitude of their reflection and their value in regional correlation. However, with increasing resolution, greater information and accuracy can be gained only by attention to the lower-amplitude returns from minor sedimentary changes.

\section{ACKNOWLEDGMENTS}

I thank M. Johns, who shared the task of shipboard data collection. Thanks also to S. G. Smith for advice, encouragement, and critical assessment of the manuscript and to $\mathrm{H}$. Boxall who helped in drafting the diagrams. Also L. Mayer, R. Wilkens, and G. Mountain for their discussion and hospitality.

This work was funded with grants from the Open University (Higher Degrees Office and Petrogenesis Research Group) and the Natural Environmental Research Council.

\section{REFERENCES}

Benson, W. E., Sheridan, R. E., et al., 1978. Site 388: lower continental rise hills. In Benson, W. E., Sheridan, R. E., et al., Init. Repts. DSDP, 44: Washington (U.S. Govt. Printing Office), 23-46.

Bryan, G. M., Markl, R. G., and Sheridan, R. E., 1980. IPOD site surveys in the Blake-Bahama basin. Mar. Geol. 35:43-63.

Hamilton E. L., 1976. Variations of density and porosity with depth in deep-sea sediments, J. Sed. Petrol. 46:280-300.

Houtz, R. E., 1973. Preliminary study of global sediment sound velocities from sonobuoy data. In Hampton L. (Ed.), Physics of Sound in Marine Sediments: New York (Plenum Press), pp. 519-535.

Jones, E. J. W., Ewing, M., Ewing, J. I., and Eittreim, S. L., 1970. Influences of Norwegian outflow water on sedimentation in the North Atlantic and Labrador Sea. J. Geophys. Res., 75:1655-1680.

Klitgord, K. D., and Grow, J. A., 1980. Jurassic seismic stratigraphy and basement structure of the western Atlantic magnetic quiet zone, Am. Assoc. Pet. Geol. Bull., 64:1658-1680.

Mayer, L. A., 1979. Deep-sea carbonates: acoustic, physical and stratigraphic properties. J. Sed. Petrol., 49:819-836.

Oehler, J. H., 1975. Origin and distribution of silica lepispheres in porcellanite from the Monterey Formation of California. J. Sed. Petrol., 45:252-257.

Shipley, T. H., 1983. Physical properties, synthetic seismograms, and seismic reflections: correlations at Deep Sea Drilling Project site 534, Blake-Bahama basin. In Sheridan, R. E., Gradstein, F. M., et al., Init. Repts. DSDP, 76: Washington (U.S. Govt. Printing Office), 653-666.

Tucholke, B. E., 1981. Geologic significance of seismic reflectors in the deep western North Atlantic basin. Woods Hole Oceanogr. Inst., Contr. No. 4459.

Tucholke, B. E., Bryan, G. M., and Ewing, J. I., 1977. Gas hydrate horizons detected in seismic profiler data from the western North Atlantic. Am. Assoc. Pet. Geol. Bull., 61:698-707.

Tucholke, B. E., Houtz, R. E., and Ludwig, W. J., 1982. Sediment thickness and depth to basement in western North Atlantic Ocean basin. Am. Assoc. Pet. Geol. Bull., 66:1384-1395.

Vail, P. R., Mitchum, R. M., Shipley, T. H., and Buffler, R. T., 1980. Unconformities in the evolution of the North Atlantic. Phil. Trans. Roy. Soc., A294:137-155.

Vail, P. R., Mitchum, R. G., Widmier, J. M., Thompson III, S., Sangree, J. B., et al., 1977. Seismic stratigraphy and global changes of sea level. In Payton C. E. (Ed.), Seismic Stratigraphy-Applications to Hydrocarbon Exploration. Am. Assoc. Pet. Geol. Mem., 26:49-116.

Weaver, F. M., and Wise, S. W., 1974. Opaline sediments of the southeastern coastal plain and Horizon A: biogenic origin. Science, 184: 899-901.

Wilkens, R. H., Schreiber, B. C., Caruso, L., and Simmons, G., in press. Influence of diagenesis on physical properties and acoustic stratigraphy on the New Jersey margin. In Poag, C. W., Watts, A. B., et al., Init. Repts. DSDP, 95: Washington (U.S. Govt. Printing Office).

Date of Initial Receipt: 26 November 1984

Date of Acceptance: 5 November 1985 

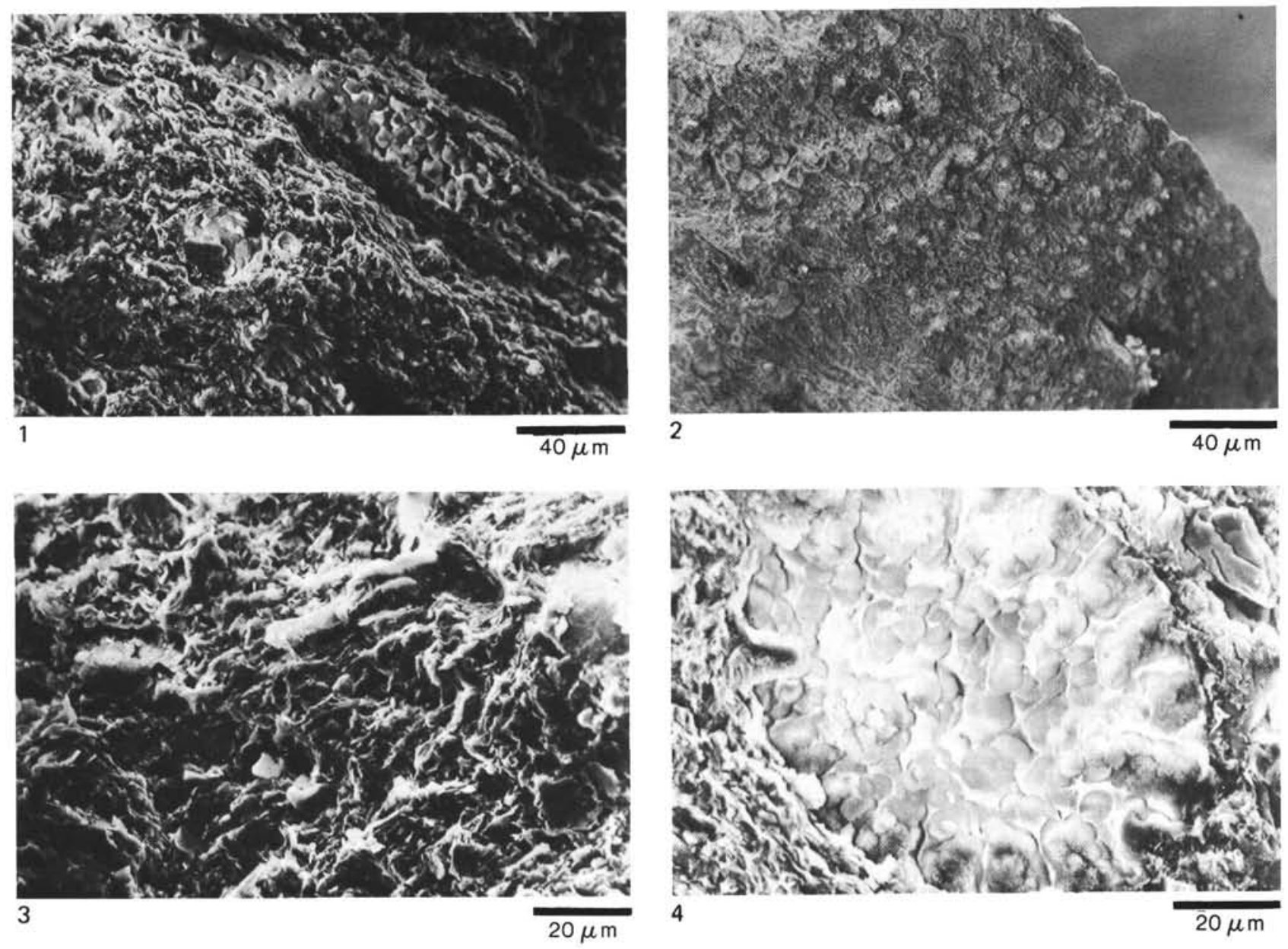

Plate 1. 1. Scanning electron micrograph of silt-rich claystone, lithologic Subunit ID, 603B-15-2, 80-81 cm. Broken surface showing typical claystone ultrafabric. 2. Scanning electron micrograph of radiolarian claystone, lithologic Unit II, 603B-16-6, 80-81 cm. Broken surface shows mottling from formation of opal-CT. 3. Detail from Fig. 2 showing lepispheres in vug and veins. Fabric clearly distinct from the overlying unit. 4. Detail from Fig. 2 showing a lepisphere-filled vug. 